\title{
Improvement and Evaluation of the TOPCOP Taxonomy of Patient Portals: Taxonomy-Evaluation-Delphi (TED) Approach
}

Michael Glöggler, MSc, MEng; Elske Ammenwerth, MSc, MET, PhD

Institute of Medical Informatics, UMIT - Private University for Health Sciences, Medical Informatics and Technology, Hall in Tirol, Austria

Corresponding Author:

Michael Glöggler, MSc, MEng

Institute of Medical Informatics

UMIT - Private University for Health Sciences, Medical Informatics and Technology

Eduard-Wallnöfer-Zentrum 1

Hall in Tirol, 6060

Austria

Phone: 43508648 ext 3809

Fax: 43508648673809

Email: michael.gloeggler@edu.umit-tirol.at

\section{Abstract}

Background: Patient portals have been introduced in many countries over the last 10 years, but many health information managers still feel they have too little knowledge of patient portals. A taxonomy can help them to better compare and select portals. This has led us to develop the TOPCOP taxonomy for classifying and comparing patient portals. However, the taxonomy has not been evaluated by users.

Objective: This study aimed to evaluate the taxonomy's usefulness to support health information managers in comparing, classifying, defining a requirement profile for, and selecting patient portals and to improve the taxonomy where needed.

Methods: We used a modified Delphi approach. We sampled a heterogeneous panel of 13 health information managers from 3 countries using the criterion sampling strategy. We conducted 4 anonymous survey rounds with qualitative and quantitative questions. In round 1, the panelists assessed the appropriateness of each dimension, and we collected new ideas to improve the dimensions. In rounds 2 and 3, the panelists iteratively evaluated the taxonomy that was revised based on round 1. In round 4, the panelists assessed the need for a taxonomy and the appropriateness of patient engagement as a distinguishing concept. Then, they compared 2 real portals with the final taxonomy and evaluated its usefulness for comparing portals, creating an initial requirement profile, and selecting patient portals. To determine group consensus, we applied the RAND/UCLA Appropriateness Method.

Results: The final taxonomy consists of 25 dimensions with 65 characteristics. Five new dimensions were added to the original taxonomy, with 8 characteristics added to already existing dimensions. Group consensus was achieved on the need for such a taxonomy to compare portals, on patient engagement as an appropriate distinguishing concept, and on the comprehensibility of the taxonomy's form. Further, consensus was achieved on the taxonomy's usefulness for classifying and comparing portals, assisting users in better understanding portals, creating a requirement profile, and selecting portals. This allowed us to test the usefulness of the final taxonomy with the intended users.

Conclusions: The TOPCOP taxonomy aims to support health information managers in comparing and selecting patient portals. By providing a standardized terminology to describe various aspects of patient portals independent of clinical setting or country, the taxonomy will also be useful for advancing research and evaluation of patient portals.

(J Med Internet Res 2021;23(10):e30701) doi: 10.2196/30701

\section{KEYWORDS}

taxonomy; classification system; patient portal; EHR portal; online EHR access; evaluation; Delphi study; electronic health records; digital health; health information; information management; user perspectives 


\section{Introduction}

\section{Background}

The delivery of knowledge-based care depends on patient engagement, where patients take an active role in their care [1-3]. Patient portals are considered a health information technology that promotes patient engagement [4-6] by providing patients with online tools to take an active role in their care [7-9]. Since patient portals are more than just static repositories for patient data $[10,11]$, they support the new vision of health services that enable patient-provider information sharing [12,13], thus contributing to empowering patients $[14,15]$, supporting shared decision making [16], and engaging patients actively in their care $[6,17]$. A patient portal is an internet-based application combining knowledge and software tools $[18,19]$ that allow patients to have autonomous access to their electronic health record (EHR) anywhere at any time [20,21]. Besides its core function of providing EHR access [22], the features of a patient portal range from viewing visit notes, requesting medication refills, appointment scheduling, access to test and lab results, secure messaging with the health provider, e-visits, or reporting patient-generated health data [17,23-26]. Patient portals are used in different organizational settings such as independent physician practices and hospitals, group practices, or large, integrated health care delivery organizations [27-29].

\section{The Need for a Taxonomy of Patient Portals}

The widespread use of the internet, rise of mobile computing, and progress in patients' technical aptness have led to an increase in the use of patient portals in various countries such as the United States, Denmark, and Australia [12,28,30]. However, there are countries where patient portals are still not widely used [31,32]. A benchmarking study presented by Ammenwerth et al [33] in 2020 analyzed the eHealth progress of 14 countries worldwide with different health systems and different levels of economic development. The study showed that the use of patient portals and the provided patient portal functionalities vary significantly between the countries. While Finland and South Korea, for example, allow patients the best access to their health record data, 6 of the 14 analyzed countries do not offer their population any access to their health data online [33].

The low use of patient portals in both developing and high-income countries [31,34] creates a problematic situation for the health informatics professionals who are responsible for strategic and tactical information technology management in their health care institution or department; we will call these professionals "health information managers." On the one hand, there already exists a very heterogeneous landscape and a broad diversity of patient portals $[12,27,35,36]$ regarding their intended deployment and functionalities [25,30,37]. In contrast, many health information managers still feel they have too little knowledge of patient portals [32]. They admit having difficulties understanding the portals' various application areas and scopes, defining their general requirements, and selecting a patient portal for their specific context or problem [32]. Health information managers are responsible for planning, organizing, and following up on all activities related to health information technology $[38,39]$. This also involves selecting, introducing, and managing patient portals for their health care institution [32].

To support health information managers with a tool for comparing patient portals and defining which general type and functionalities of patient portals they need, we developed the TOPCOP taxonomy (Taxonomy of Patient Portals based on Characteristics of Patient Engagement) [32]. The need for such a patient portal taxonomy had already been stressed in a recently published Cochrane Review on the impact of patient portals [40]. The TOPCOP taxonomy is shown in Figure 1. A comprehensive description of the dimensions is published elsewhere [32]. 
Figure 1. The TOPCOP taxonomy of patient portals [32]: A patient portal is described regarding 7 aspects that cover 20 dimensions. A patient portal can be described by selecting 1 characteristic per dimension.

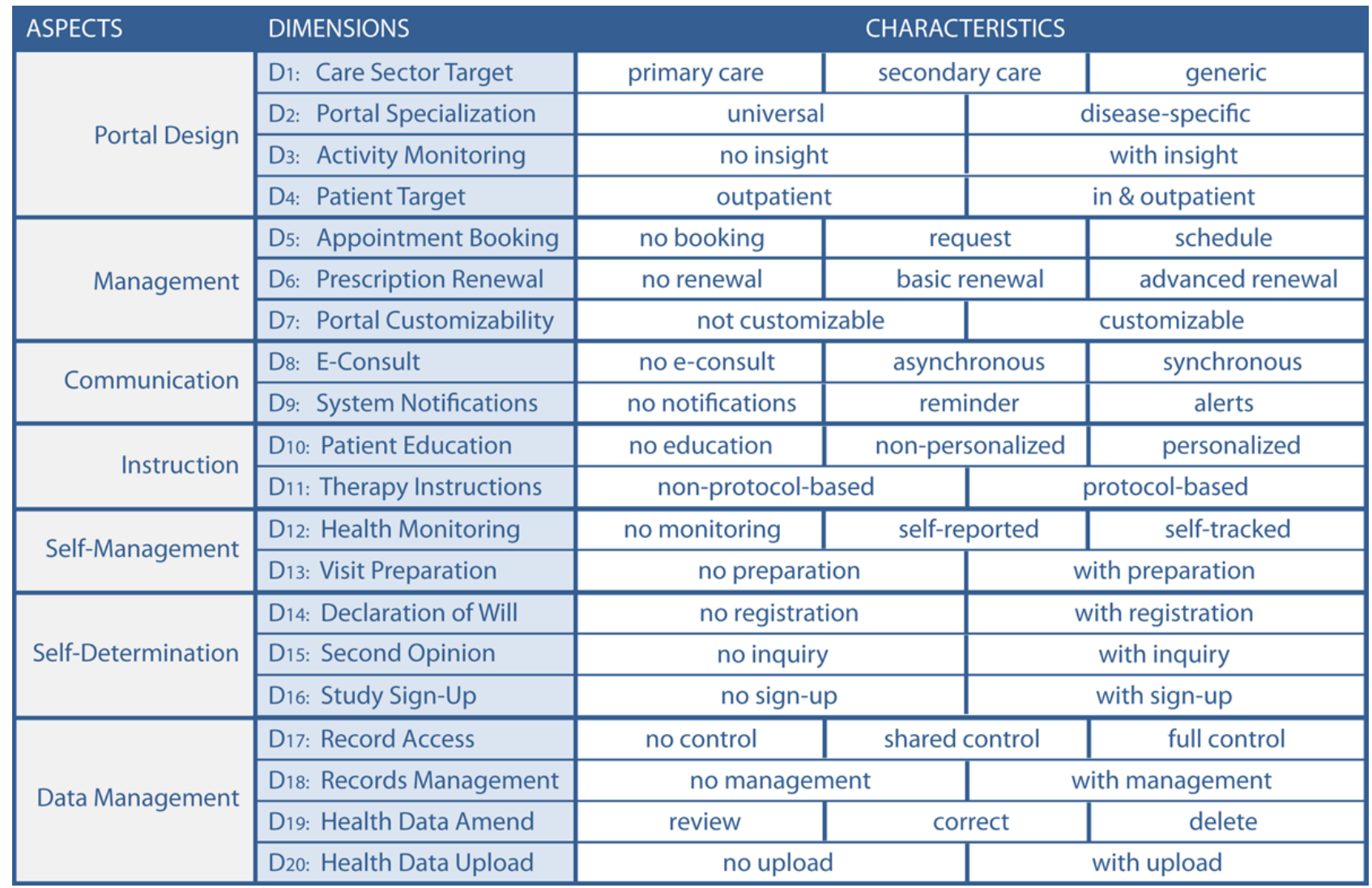

\section{The Development of the TOPCOP Taxonomy}

A taxonomy is a classification system to classify similar objects of a domain into groups based on distinct characteristics and offers a set of decision rules [41-44]. The reduction of complexity, identifying similarities and differences among objects $[45,46]$, and the understanding of interrelationships are major advantages of taxonomies $[44,47,48]$. Taxonomies thus support researchers and practitioners in better understanding a domain and distinguishing among its objects [49,50]. The TOPCOP taxonomy was built by applying the formal taxonomy-building method proposed by Nickerson et al [51]. This method specifies the necessary steps and integrates 2 optional, iterative development approaches to conceptionally and empirically build and empirically evaluate a taxonomy [51,52]. The TOPCOP taxonomy was created conceptionally based on a literature review to assess the characteristics and functionalities of patient portals [32]. It was evaluated empirically by classifying patient portals offered on the market and health providers' portals online [32].

A taxonomy is determined by the user's intended purpose, which guides the taxonomy's development by focusing on the specific phenomenon of interest [50,53]. Different users or different purposes may therefore lead to a different taxonomy [51,54]. We created the TOPCOP taxonomy for health information managers to classify and compare patient portals [32]. Further, the taxonomy should serve the health information managers in defining the general type and functionalities of patient portals and should help them select the most suitable solution offered on the market. The dimensions were built to distinguish among patient portals with the scope on patient engagement.

Since there is no objective metric to define the usefulness or quality of a taxonomy $[44,51,55]$, the method by Nickerson et al [51] provides a set of conditions to determine usefulness. Applying these conditions during the building process, the taxonomy's usefulness was empirically validated by classifying all patient portals of interest with the taxonomy [32].

\section{The Requirement for a Taxonomy's Evaluation}

According to design science research, taxonomies are fundamental design artifacts to provide knowledge and understanding of a problem domain [49]. In design science research, the design process for an artifact is divided first into building and then into evaluating [56,57]. Following the design science research paradigm, one suitable criterion to evaluate a taxonomy is by having users assess its usefulness in achieving its intended purpose [58,59]. Therefore, we now wanted to evaluate and further improve the TOPCOP taxonomy together with the projected users, guided by the evaluation criteria of the taxonomy's usefulness related to its intended purpose.

\section{Methods}

\section{The Delphi Technique}

\section{Overview}

We applied a modified Delphi approach to evaluate the TOPCOP taxonomy. The Delphi technique is a qualitative method, first described by Dalkey and Helmer [60]. It is used 
in many research areas such as business, policy science, education, health sciences, information science, and health informatics [61-65]. Since there is no consistency in the methods used for evaluating a taxonomy [49], we opted for the Delphi technique because it is commonly agreed that Delphi research elicits sound scientific evidence [66]. Further, various researchers argue that qualitative methods may be particularly appropriate for evaluating design artifacts [67] including taxonomies.

The Delphi technique was particularly suited for our study as it aims to obtain a highly reliable consensus of group opinions on the research items [68] and has been used by researchers to evaluate taxonomies in the past [69-73]. The method is adequate to explore a domain [63], elicit new evidence, and generate new ideas $[68,74]$. Since the aim of this study was to collect new ideas on dimensions, improve the existing TOPCOP taxonomy, and achieve consensus on the appropriateness of the dimensions by the taxonomy's users, we considered Delphi to be the best approach as it goes beyond collecting simple intuitive expert opinions [75]. Further, the method applies relatively rigorous control over the interviewing methods, the controlled opinion feedback, and the summary of the results [76].

Using a series of survey rounds delivered in multiple iterations, interspersed with controlled opinion feedback [76], we were able to collect new ideas and correlate the panelists' opinions on our research items anonymously to improve the taxonomy $[60,62,75]$. Further, the method is highly flexible [77], accommodating many variations [78-80], and can be used to conduct evaluation studies [81], allowing us to adapt and modify the technique to evaluate our taxonomy. While the classic Delphi aims to generate opinions from experts to make forecasts $[60,82]$, we wanted to collect and correlate the opinions of the taxonomy's users to improve and evaluate the TOPCOP taxonomy. We now outline the methodological approaches applied to our study.

\section{Selection of the Panelists}

There are no agreed standards on how to select the participants for Delphi studies [75,83]. We applied a criterion sampling strategy, which is a preferred approach in many Delphi studies [84]. Since the taxonomy should help health information managers to compare patient portals, eligible individuals had to hold a role within a health provider's organization where they would be actively involved in a patient portal's selection process. We applied the snowball method [85] to reach out to potential panelists involving patient portal vendors known from the taxonomy development phase [32]. The snowball method has been legitimized and used in many other Delphi studies $[75,86,87]$. Since there is no standard method for identifying the best number of individuals for inclusion in a Delphi study $[86,87]$, we determined this number based on our research aim and availability of expertise as proposed by several researchers [88-90].

We selected 13 health information managers from Germany, Switzerland, and Austria as we wanted to include panelists from countries with diverse health systems and different progress in eHealth [31,33]. By sampling panelists from different countries but who speak the same language, we aimed to avoid a possible language bias as the survey questions and the complex explanations of the dimensions could otherwise be misinterpreted [91]. Since homogeneous panels tend to find consensus more quickly than heterogeneous panels [92,93], we wanted to enhance credibility through diversity, considering the broadest possible range of participants' experiences with patient portals and geographic diversity to depict the real situation of different health systems. The educational backgrounds of health information managers are not uniform but may be diverse [39]. We, therefore, included panelists with different educational backgrounds in our sample. In Table 1, we present the final panel. 
Table 1. Study sample selection.

\begin{tabular}{|c|c|c|c|c|c|c|c|c|c|}
\hline $\begin{array}{l}\text { Panelist } \\
\text { number }\end{array}$ & Country & Gender & $\mathrm{AE}^{\mathrm{a}}$ & $\mathrm{PB}^{\mathrm{b}}$ & Role & $\begin{array}{l}\mathrm{WE}^{\mathrm{c}} \\
\text { (years) }\end{array}$ & $\begin{array}{l}\mathrm{EPP}^{\mathrm{d}} \\
\text { (years) }\end{array}$ & $\mathrm{INST}^{\mathrm{e}}$ & $S P P^{f}$ \\
\hline 1 & Austria & Male & MEng & Computer engineer & Head of department & 27 & 5 & $\mathrm{HCP}^{\mathrm{g}}$ & Yes \\
\hline 2 & Austria & Male & BEng & Computer scientist & Head of department & 15 & 5 & $\mathrm{HCP}$ & Yes \\
\hline 3 & Austria & Female & BEng & Medical informatics & Project manager & 26 & 1 & $\mathrm{HCP}$ & Yes \\
\hline 4 & Austria & Male & $\mathrm{PhD}$ & Electronics engineer & Head of department & 25 & 1 & $\mathrm{HCP}$ & Yes \\
\hline 5 & Austria & Male & MEng & Medical informatics & Head of department & 12 & 1 & $\mathrm{HCP}$ & Yes \\
\hline 6 & Austria & Male & $\mathrm{BSc}$ & Bioengineering & Head of department & 33 & 10 & $\mathrm{HCP}$ & Yes \\
\hline 7 & Switzerland & Male & BEng & Medical informatics & System engineer & 10 & 16 & $\mathrm{HCP}$ & Yes \\
\hline 8 & Switzerland & Female & MSc & eHealth management & Researcher & 13 & 3 & $\mathrm{HCO}^{h}$ & No \\
\hline 9 & Switzerland & Male & MSc & Medical informatics & Head of department & 28 & 2 & HCP & Yes \\
\hline 10 & Germany & Male & $\mathrm{BSc}$ & System engineer & Head of department & 20 & 7 & $\mathrm{HCP}$ & Yes \\
\hline 11 & Germany & Male & $\mathrm{PhD}$ & Medical informatics & Researcher & 10 & 6 & $\mathrm{HCP}$ & Yes \\
\hline 12 & Germany & Male & MSc & Medical informatics & Head of eHealth & 13 & 8 & $\mathrm{HCO}$ & No \\
\hline 13 & Germany & Female & MD & Physician & Head of eHealth & 26 & 8 & $\mathrm{HCP}$ & Yes \\
\hline
\end{tabular}

${ }^{\mathrm{a}} \mathrm{AE}$ : academic education.

${ }^{\mathrm{b}} \mathrm{PB}$ : professional background.

${ }^{\mathrm{c}} \mathrm{WE}$ : work experience.

${ }^{\mathrm{d}}$ EPP: experience with patient portals.

eINST: institution.

${ }^{\mathrm{f}} \mathrm{SPP}$ : would be involved in selecting a patient portal.

${ }^{\mathrm{HCP}}$ : health care provider.

${ }^{\mathrm{h}} \mathrm{HCO}$ : health care organization.

\section{Determination of the Number of Survey Rounds for Evaluation}

As per common agreement, the number of survey rounds is guided by the nature of the study and the level of consensus achieved among the participants during each iteration [75,76,94]. Our study was planned to be performed in 4 assessment cycles, guided by the elicitation of evidence and the achievement of group consensus. In the first 3 rounds, we aimed to collect ideas to improve the taxonomy and to achieve group consensus on every single dimension of the taxonomy related to its appropriateness for comparing patient portals. In round 4 , the panelists were asked to evaluate the final taxonomy as a whole as proposed by Wiliam and Black [95], related to its intended use. The survey rounds were performed between January 2021 and April 2021.

\section{Achievement of Consensus-the RAND/UCLA Appropriateness Method}

The goal of the Delphi technique is to achieve a consensus of opinions from a group of individuals concerning a particular topic or task $[87,96,97]$. However, there is no general agreement on what statistical aggregation or method is best to determine consensus [98]. Since we wanted to assess the appropriateness of the taxonomy, we considered the concept of the
RAND/UCLA Appropriateness Method, called RAM [99], most suitable to determine achievement of consensus in our study. While the RAM method is widely used to determine the appropriateness of health care services [100,101], we applied the model's consensus measure to evaluate the appropriateness of the taxonomy's dimensions for classifying and comparing patient portals.

The RAM method uses the median to measure the central tendency of the panelists' ratings, and ratings should be spread over a 1-9 rating scale $[89,99]$. The RAM method offers various conditions to constitute disagreement of opinions [99], from which we chose DS9, the strictest definition of disagreement [99]. DS9 means that a dimension is appropriate for comparing patient portals if group consensus with a median of 7-9 without disagreement is achieved. Considering all ratings, disagreement exists when at least one rating is a 1 and at least one is a 9. A dimension is considered uncertain for comparing patient portals if group consensus achieves a median of 4-6 or if there is any median with disagreement. A dimension is considered inappropriate for comparing patient portals if group consensus achieves a median of 1-3 without disagreement. The DS9 measure was applied for all assessments to determine achievement of group consensus. The DS9 measure is summarized in Table 2. 
Table 2. The DS9 RAND/UCLA Appropriateness Measure with dispersion: considering all ratings, at least one is a 1 , and at least one is a 9.

\begin{tabular}{lll}
\hline Appropriateness & Panel median & Dispersion condition \\
\hline Appropriate & $7-9$ & Without disagreement \\
Uncertain & $4-6$ & Or any median with disagreement \\
Inappropriate & $1-3$ & Without disagreement
\end{tabular}

\section{Applying Anonymity to Express Opinions Freely}

The complete study was conducted anonymously, which means that none of our panelists knew who participated in the survey and no interaction was possible between them. Anonymity allowed greater freedom for our panelists to express their views $[102,103]$ and opinions freely as it avoids the problem of dominant contributors possibly influencing individual opinions [104,105].

\section{Introductory Conversations to Enhance Adherence of Panelists and to Create a Common Understanding of the Research Topics}

We were aware of the known problem that participants might drop out [77] due to the time-consuming commitment, unforeseen shortage of time, loss of interest, or distraction between the rounds, risking a poor response rate [83]. To promote motivation and strengthen adherence, we conducted an introductory conversation with each panelist separately, as proposed by Daniel and White [106], using the Zoom video conferencing tool [107]. The scope was to give the panelists the possibility to ask questions related to the aim of the study, the research process, and their role in the study and to create a common understanding on all topics.

\section{Set-Up of the Online Survey}

All interviews were carried out with online questionnaires using a commercial survey product [108]. The survey was piloted by 4 different persons other than the researchers. The survey contained quantitative and qualitative questions. The quantitative ratings served to assess the dimensions' appropriateness (rounds
1-3) and the final taxonomy as a whole (round 4). To assess the dimensions, we presented only 1 dimension with its characteristics per page (example Figure 2) and added a comprehensive definition of the existing characteristics and the newly proposed characteristics to assure that all panelists had the same understanding of the dimensions.

We provided a Likert scale ranging from 1 to 9 as proposed by RAM [99] for assessment. The open-ended qualitative questions provided in rounds 1-3 allowed the panelists to comment on their ratings if the rating fell into values between 1 and 6 . Further, the qualitative questions allowed the panelists to improve the taxonomy by making proposals for new characteristics or dimensions. All proposals had to follow the knowledge-guiding principle of being suitable for promoting patient engagement. The comments and proposals were presented in the subsequent round for the panelists' reflection. Comments related to ratings, to changes of existing dimensions, or to new characteristics and dimensions were assigned accordingly. The comments were quoted verbatim with no changes made to the original. At the beginning of each survey round, we provided short guidelines on evaluating the research items and presented the results of the previous round. In round 1 , we presented the initial TOPCOP taxonomy (Figure 1). In round 2, we presented the ratings from the first round (Multimedia Appendix 1) demonstrating achievement of group consensus. In round 3, we presented the results from the second round demonstrating for which new characteristics and dimensions group consensus was achieved or not achieved (Multimedia Appendix 2). In round 4, we presented the jointly improved, final taxonomy.

Figure 2. Example for the display of a single dimension for rating.

\begin{tabular}{|l|c|c|c|}
\hline DIMENSIONS & \multicolumn{3}{c|}{ CHARACTERISTICS } \\
\hline Portal Type & primary care & secondary care & generic \\
\hline
\end{tabular}

\section{The 4 Rounds of the TOPCOP Taxonomy's Improvement and Evaluation}

\section{Round 1: Assessment of the Existing Dimensions and Proposals for Improvement of the Taxonomy}

In the first round, the panelists were asked to assess the appropriateness of the existing TOPCOP taxonomy's dimensions for classifying and comparing patient portals. Further, they were asked to propose unsuitable or missing characteristics related to the existing dimensions and to suggest new dimensions to improve the taxonomy guided by their needs.

\section{Round 2: Assessment of the Newly Proposed Characteristics and Dimensions of Round 1}

In the second round, the panelists were first asked to assess the proposals of round 1 for new characteristics to refine existing dimensions. Each proposal was presented with all existing and all new characteristics (Multimedia Appendix 3). Related to the proposals of adding new characteristics to the existing dimensions or merge characteristics, we stressed that the panelists should evaluate the appropriateness of the new or merged characteristic of improving the existing dimension to compare patient portals. Then, the panelists were asked to assess the appropriateness of the new dimensions proposed in round 1 for classifying and comparing patient portals. 


\section{Round 3: Re-Evaluation of Dimensions Where Group Consensus Was Not Achieved in Previous Rounds}

In round 3 , the panelists were asked to re-evaluate those dimensions and characteristics proposed in round 1 but where no group consensus could be reached in round 2. From some panelists' comments, we understood that their assessments were guided by national legal requests rather than by evaluating a general area of application. We, therefore, added a note stressing that the scope of this study was to create a generally applicable taxonomy and that specific national requirements should not guide the rating. Since the panelists were to re-evaluate dimensions already assessed in round 2, we provided all panelists with their first rating compared to the group ratings (Figure 3) as recommended by RAM [99]. This was intended to help them better reflect on their rating considering the group opinion.

Figure 3. Example of a panelist's rating in comparison with the group ratings.

\section{Dimension: Account Protection}

$\begin{array}{llllllll}\text { Frequency of values } & 3 & 1 & 1 & 1 & 3 & 8 & 3\end{array}$

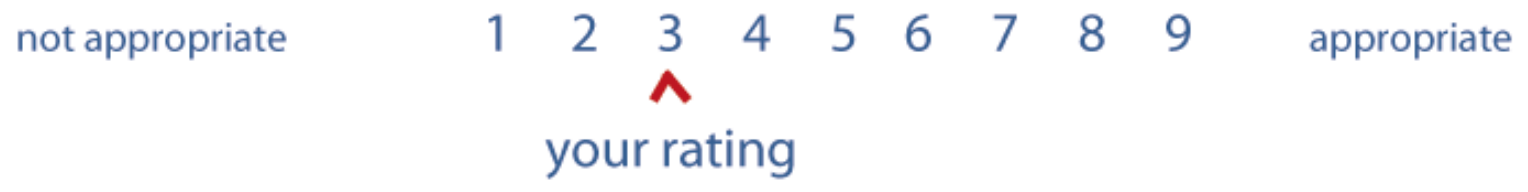

\section{Round 4: Evaluation of the Final TOPCOP Taxonomy as a Whole}

Since a taxonomy is complete and adequate when it satisfies the requirements of the purpose for which it was built [58], in round 4, the panelists were asked to evaluate the usefulness of the final taxonomy as a whole [109], related to its intended use. Round 4 was divided into 2 consecutive steps: first performing a case study and then assessing the taxonomy's usefulness.

First, evaluation is based on comparison [110]. Therefore, the panelists were requested to classify and compare 2 real-world patient portals with the final TOPCOP taxonomy to test its usefulness in a case study. We provided the panelists with 2 anonymized product descriptions from important software companies along with instructions on how to carry out the comparison. Both patient portals could be used for any care sector. However, one was a tethered patient portal while the other was an integrated patient portal. We selected these 2 patient portals because they differ in many characteristics, allowing the panelists to see the taxonomy's usefulness in comparing very different patient portals.

Second, after the case study was performed, the panelists were asked to assess the usefulness of the taxonomy as a whole. To investigate the panelists' opinions related to taxonomies for patient portals, we started with the following questions: (Q1) How important do you consider the need for a taxonomy for comparing patient portals? (Q2) How suitable do you consider patient engagement as a guiding concept for comparing patient portals?

Further, the health information managers were asked to make proposals for other guiding concepts that they considered useful to compare patient portals. Since we determined patient engagement as a guiding concept to distinguish among patient portals for the TOPCOP taxonomy, we aimed to collect alternative proposals suitable for future research: (Q3) What other guiding concepts may be appropriate for comparing patient portals?

To assess the taxonomy's usefulness as a whole [111], 6 research questions related to the performed case study were presented. Since understanding an artifact is a fundamental requirement for its usefulness, the panelists were first asked to evaluate whether the final taxonomy was understandable: (Q4) How understandable is the form and structure of the final taxonomy? Then, they were asked to assess whether the improved TOPCOP taxonomy is useful related to its intended use: (Q5) How useful is the final taxonomy for classifying patient portals following patient engagement? (Q6) How useful is the final taxonomy for comparing patient portals following patient engagement? (Q7) How useful is the final taxonomy for assisting you in better understanding patient portals based on characteristics supporting patient engagement? (Q8) How useful is the final taxonomy for creating an initial requirement profile for patient portals based on characteristics supporting patient engagement? (Q9) How useful is the final taxonomy for selecting patient portals offered on the market based on characteristics supporting patient engagement?

Question Q3 was set up as an open-ended question to collect the panelists' proposals in the best possible way [112]. To categorize the proposals, we analyzed the responses by applying the summarizing content analysis [113], an inductive analysis method proposed by Mayring [114]. All other items were assessed by applying the RAM approach [99].

\section{Results}

\section{Results of Round 1: Assessment of the Existing Dimensions and Proposals for Improvement of the Taxonomy}

The panelists were asked to evaluate the TOPCOP taxonomy by assessing every single dimension related to its 
appropriateness for classifying and comparing patient portals. In Figure 4, we present the assessment for the 20 dimensions of the initial TOPCOP taxonomy (Figure 1) indicating the median for each dimension. All 13 panelists evaluated all 20 dimensions. Since each dimension's median ranged between 7 and 9 without disagreement, group consensus on the dimensions' appropriateness was achieved for all 20 dimensions [99].

Figure 4. Achieved consensus for the existing dimensions of the TOPCOP taxonomy after round 1 . The grey column shows the median value without disagreement. All 13 panelists assessed all dimensions.

\section{ASSESSED DIMENSIONS}

RATINGS

\begin{tabular}{|l|llllll|l|llllll|}
\hline D1: Care Sector Target & 7 & 7 & 7 & 8 & 8 & 9 & 9 & 9 & 9 & 9 & 9 & 9 & 9 \\
\hline D2: Portal Specialization & 6 & 7 & 7 & 8 & 8 & 8 & 8 & 8 & 8 & 9 & 9 & 9 & 9 \\
\hline D3: Activity Monitoring & 5 & 6 & 7 & 7 & 8 & 8 & 8 & 9 & 9 & 9 & 9 & 9 & 9 \\
\hline D4: Patient Target & 5 & 5 & 7 & 7 & 7 & 7 & 8 & 8 & 8 & 9 & 9 & 9 & 9 \\
\hline D5: Appointment Booking & 8 & 8 & 8 & 8 & 9 & 9 & 9 & 9 & 9 & 9 & 9 & 9 & 9 \\
\hline D6: Prescription Renewal & 2 & 6 & 7 & 7 & 7 & 7 & 8 & 8 & 8 & 9 & 9 & 9 & 9 \\
\hline D1: Portal Customizability & 5 & 6 & 7 & 7 & 7 & 7 & 8 & 8 & 9 & 9 & 9 & 9 & 9 \\
\hline D8: E-Consult & 7 & 8 & 8 & 8 & 8 & 8 & 9 & 9 & 9 & 9 & 9 & 9 & 9 \\
\hline D9: System Notifications & 6 & 7 & 8 & 8 & 8 & 8 & 8 & 8 & 9 & 9 & 9 & 9 & 9 \\
\hline D10: Patient Education & 7 & 7 & 7 & 8 & 8 & 8 & 9 & 9 & 9 & 9 & 9 & 9 & 9 \\
\hline D11: Therapy Instructions & 5 & 5 & 7 & 7 & 7 & 7 & 8 & 8 & 8 & 8 & 9 & 9 & 9 \\
\hline D12: Health Monitoring & 7 & 7 & 7 & 8 & 8 & 9 & 9 & 9 & 9 & 9 & 9 & 9 & 9 \\
\hline D13: Visit Preparation & 7 & 7 & 7 & 8 & 8 & 8 & 8 & 9 & 9 & 9 & 9 & 9 & 9 \\
\hline D14: Declaration of Will & 6 & 6 & 7 & 7 & 7 & 8 & 8 & 8 & 8 & 9 & 9 & 9 & 9 \\
\hline D15: Second Opinion & 4 & 7 & 7 & 7 & 7 & 7 & 7 & 7 & 7 & 8 & 9 & 9 & 9 \\
\hline D16: Study Sign-Up & 5 & 6 & 7 & 7 & 7 & 7 & 7 & 7 & 7 & 8 & 8 & 9 & 9 \\
\hline D17: Record Access & 6 & 7 & 7 & 9 & 9 & 9 & 9 & 9 & 9 & 9 & 9 & 9 & 9 \\
\hline D18: Records Management & 3 & 5 & 7 & 8 & 8 & 8 & 8 & 9 & 9 & 9 & 9 & 9 & 9 \\
\hline D19: Health Data Amend & 7 & 7 & 8 & 8 & 9 & 9 & 9 & 9 & 9 & 9 & 9 & 9 & 9 \\
\hline D20: Health Data Upload & 7 & 8 & 8 & 8 & 9 & 9 & 9 & 9 & 9 & 9 & 9 & 9 & 9 \\
\hline
\end{tabular}

Further, the panelists were asked to propose unsuitable and missing characteristics to refine the existing dimensions and to suggest new dimensions to improve the taxonomy.
Two panelists proposed refining dimension D6 Prescription Renewal by merging the characteristics "basic renewal" and "advanced renewal" to create the characteristic "with renewal" instead. They argued that differentiating the dimension into the initial 2 characteristics is confusing rather than strengthening 
the distinguishability of patient portals. Seven panelists proposed 8 new characteristics to improve the existing dimensions D1, D2, D5, D6, D8, D9, D11, and D12 (Figure 5 shows the content of each dimension). Five panelists proposed the new dimensions

Account Protection, App Expandability, Medical Specialty, Medication Summary, Portal Type, and Web Accessibility to enhance the taxonomy. We present all the proposals for improvement of round 1 in Figure 5.

Figure 5. Proposals from round 1 for new characteristics and dimensions to improve the taxonomy.

\begin{tabular}{|c|c|c|c|c|c|}
\hline DIMENSIONS & \multicolumn{5}{|c|}{ CHARACTERISTICS } \\
\hline D1: Care Sector Target & primary care & $\mathrm{sec}$ & dary care & tertiary are & generic \\
\hline D2: Portal Specialization & \multicolumn{2}{|l|}{ universal } & \multicolumn{2}{|c|}{ extended } & disease-specific \\
\hline D3: Activity Monitoring & \multicolumn{3}{|c|}{ no insight } & \multicolumn{2}{|c|}{ with insight } \\
\hline D4: Patient Target & \multicolumn{3}{|c|}{ outpatient } & \multicolumn{2}{|c|}{ in \& outpatient } \\
\hline D5: Appointment Booking & no booking & \multicolumn{2}{|c|}{ request } & schedule & hybrd \\
\hline D6: Prescription Renewal & \multicolumn{3}{|c|}{ no renewal } & \multicolumn{2}{|c|}{ whthenewal } \\
\hline D7: Portal Customizability & \multicolumn{3}{|c|}{ not customizable } & \multicolumn{2}{|c|}{ customizable } \\
\hline D8: E-Consult & no e-consult & \multicolumn{2}{|c|}{ asynchronous } & synchronous & both \\
\hline D9: System Notifications & no notifications & \multicolumn{2}{|c|}{ notifations } & reminder & alerts \\
\hline D10: Patient Education & \multicolumn{2}{|l|}{ no education } & \multicolumn{2}{|c|}{ non-personalized } & personalized \\
\hline D11: Therapy Instructions & \multicolumn{2}{|c|}{$n o n s t r a n n$} & \multicolumn{2}{|c|}{ non-protocol-based } & protocol-based \\
\hline D12: Health Monitoring & no monitoring & \multicolumn{2}{|c|}{ self-reported } & self-tracked & comblned \\
\hline D13: Visit Preparation & \multicolumn{3}{|c|}{ no preparation } & \multicolumn{2}{|c|}{ with preparation } \\
\hline D14: Declaration of Will & \multicolumn{3}{|c|}{ no registration } & \multicolumn{2}{|c|}{ with registration } \\
\hline D15: Second Opinion & \multicolumn{3}{|c|}{ no inquiry } & \multicolumn{2}{|c|}{ with inquiry } \\
\hline D16: Study Sign-Up & \multicolumn{3}{|c|}{ no sign-up } & with & n-up \\
\hline D17: Record Access & no control & & sharec & ntrol & ull control \\
\hline D18: Records Management & no mar & lage & ent & with $\mathrm{m}$ & agement \\
\hline D19: Health Data Amend & review & & & & delete \\
\hline D20: Health Data Upload & no $u$ & ploa & & with & load \\
\hline D21: Account Protection & low & & me & & strong \\
\hline D22: App Expandability & not exp & and & & & idable \\
\hline D23: Medical Specialty & & eric & & & alized \\
\hline D24: Medication Summary & no su & $\mathrm{mm}$ & & with & Immary \\
\hline D25: Portal Type & teth & erec & & & rated \\
\hline D26: Web Accessibility & not su & opor & & & orted \\
\hline
\end{tabular}

Legend

Existing dimension $\square$ Existing characteristic $\quad$ New characteristc for existing dimension
New dimension

\section{Results of Round 2: Assessment of the Newly Proposed Characteristics and Dimensions of Round 1}

In round 2, the panelists had to assess the proposals from round 1 (Figure 5). They were asked to evaluate the merger of the characteristics of dimension D6. Further, they assessed the appropriateness of the suggested characteristics of dimensions D1, D2, D5, D8, D9, D11, and D12.

All 13 panelists assessed the proposed 8 characteristics and justified their rating whenever it fell between 1 and 6 . As demonstrated in Figure 6, the median assessment for the appropriateness of all changes ranged between 7 and 9 without 
disagreement. Therefore, all 8 characteristics were appropriate for improving the taxonomy and became part of the taxonomy [99].

The panelists were further requested to evaluate the appropriateness of the proposed dimensions D21 Account Protection, D22 App Expandability, D23 Medical Specialty, D24 Medication Summary, D25 Portal Type, and D26 Web Accessibility.

In Figure 7, we demonstrate that for all these dimensions, the median ranged between 7 and 8 . However, the condition for disagreement [99] was fulfilled for dimensions D21 Account Protection and D26 Web Accessibility. Therefore, only dimensions D22, D23, D24, and D25 were considered appropriate for improving the taxonomy and became part of the taxonomy. Since no panelist made any proposal for changing an existing dimension or for a new dimension in round 2, only dimensions D21 and D26 became subject to re-evaluation in round 3 .

In Figure 8, we present the taxonomy in progress after round 2 showing for which characteristics group consensus was achieved and for which dimensions no group consensus was achieved.

Figure 6. Achieved consensus by all 13 panelists on new characteristics for existing dimensions proposed in round 1 . The grey column shows the median without disagreement. *New characteristics to improve the dimension.

\begin{tabular}{|l|l|llllll|l|llllll|}
\hline \multicolumn{1}{|c|}{ DIMENSIONS } & CHARACTERISTICS & \multicolumn{11}{|c|}{ RATINGS } \\
\hline D1: Care Sector Target & tertiary care & 5 & 6 & 8 & 8 & 8 & 8 & 8 & 9 & 9 & 9 & 9 & 9 & 9 \\
\hline D2: Portal Specialization & extended & 2 & 4 & 5 & 6 & 7 & 7 & 7 & 7 & 8 & 8 & 9 & 9 & 9 \\
\hline D5: Appointment Booking & hybrid & 2 & 4 & 6 & 7 & 7 & 8 & 9 & 9 & 9 & 9 & 9 & 9 & 9 \\
\hline D6: Prescription Renewal & renewal & 4 & 7 & 7 & 7 & 8 & 8 & 8 & 8 & 8 & 9 & 9 & 9 & 9 \\
\hline D8: E-Consult & both & 2 & 6 & 7 & 7 & 8 & 8 & 8 & 8 & 9 & 9 & 9 & 9 & 9 \\
\hline D9: System Notifications & notifications & 2 & 6 & 7 & 7 & 7 & 7 & 7 & 8 & 8 & 9 & 9 & 9 & 9 \\
\hline D11: Therapy Instructions & no instructions & 7 & 7 & 7 & 8 & 8 & 8 & 8 & 8 & 9 & 9 & 9 & 9 & 9 \\
\hline D12: Health Monitoring & combined & 2 & 7 & 7 & 8 & 8 & 8 & 9 & 9 & 9 & 9 & 9 & 9 & 9 \\
\hline
\end{tabular}

Figure 7. Achieved consensus by all 13 panelists on new dimensions proposed in round 1.

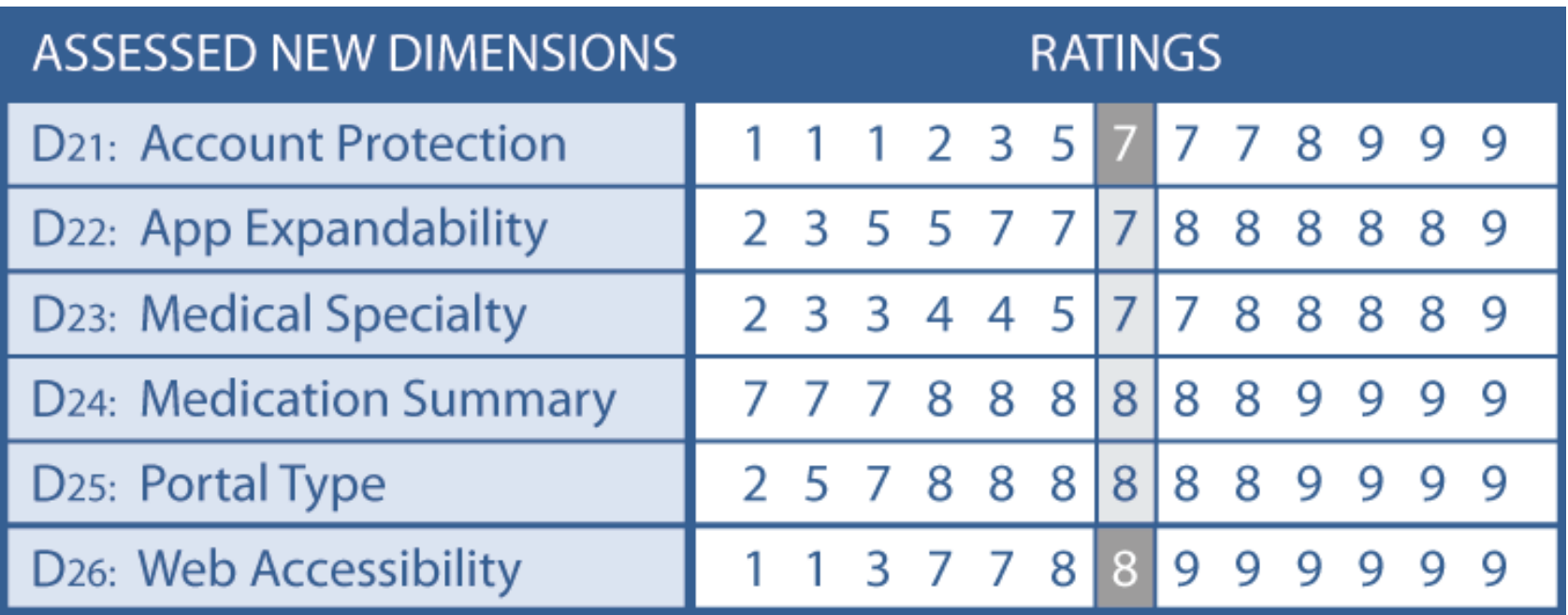

Legend

Median without disagreement.

Median with disagreement: considering all ratings, at least one is a 1 , and at least one is a 9. 
Figure 8. The TOPCOP taxonomy in progress after round 2 .

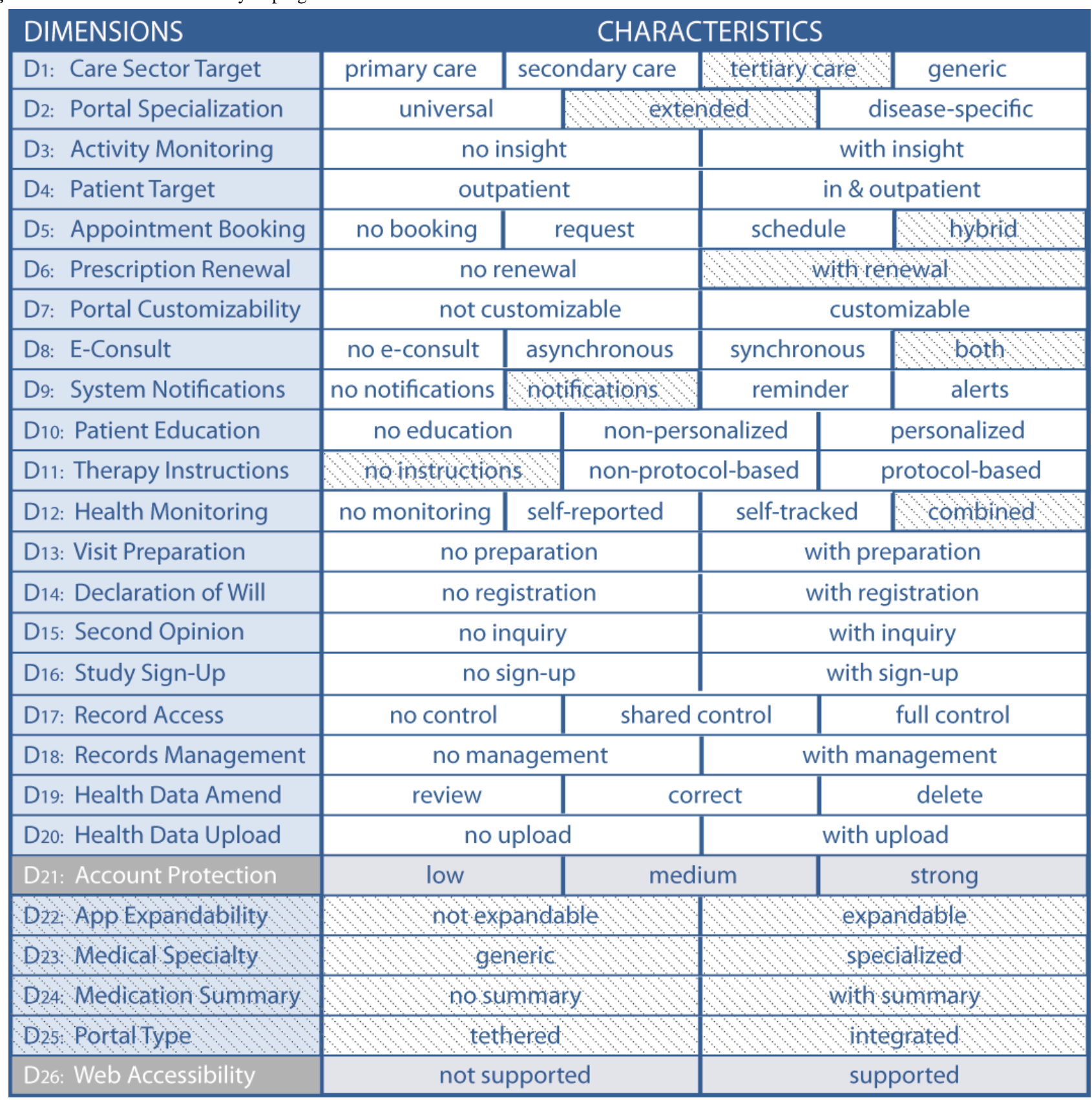

Legend $\mathrm{S}$ Proposed characteristic with consensus.

Proposed characteristic without consensus. Proposed dimension with consensus.

\section{Results of Round 3: Re-Evaluation of Dimensions Where Group Consensus Was Not Achieved in Previous Rounds}

In round 3, the panelists were asked to again assess the new dimensions D21 Account Protection and D26 Web Accessibility as group consensus was not achieved in round 2 . All 13 panelists assessed both dimensions.

As demonstrated in Figure 9, a median of 8 without disagreement [99] was achieved for dimension D26. Dimension D26 was therefore appropriate and became part of the taxonomy. For dimension D21, a median of 7 was achieved. However, as at least one rating is a 1 and at least one rating is a 9, disagreement existed among the panelists [99]. All 5 panelists who assessed dimension D21 with values of 1 and 3 argued consistently that a patient portal must provide the highest data protection due to legal or patient requirements. Therefore, as strong account protection is a mandatory requirement, dimension D21 is not appropriate for distinguishing among patient portals. Comparing the ratings of dimension D21 for rounds 2 and 3 showed that, besides the fact that disagreement was re-confirmed in round 3, 3 ratings deteriorated (Figure 9), which means that group consensus converged even more strongly towards disapproval of dimension D21. To avoid the known risk of fatiguing the panelists with too many evaluation rounds [92], we did not launch another evaluation round. Since no group 
consensus was achieved, dimension D21 was not integrated into the taxonomy.

After assigning the new dimensions to suitable aspects and organizing and numbering the dimensions accordingly, the final
TOPCOP taxonomy resulted in 25 dimensions based on 65 characteristics assigned to 7 aspects and is presented in Figure 10. In Multimedia Appendix 4, we provide a detailed description of the dimensions and characteristics.

Figure 9. Achieved consensus by all 13 panelists on dimensions D21 and D26 after round 3 in comparison with the consensus in round 2.

\section{REASSESSED NEW DIMENSIONS \\ RATINGS}

Results of round 2

\begin{tabular}{|l|llllll|l|llllll|}
\hline D21: Account Protection & 1 & 1 & 1 & 2 & 3 & 5 & 7 & 7 & 7 & 8 & 9 & 9 & 9 \\
\hline D26: Web Accessibility & 1 & 1 & 3 & 7 & 7 & 8 & 8 & 9 & 9 & 9 & 9 & 9 & 9 \\
\hline
\end{tabular}

Results of round 3

\begin{tabular}{|l|llllll|l|llllll|}
\hline D21: Account Protection & 1 & 1 & 1 & 3 & 3 & 5 & 7 & 7 & 7 & 7 & 8 & 8 & 9 \\
\hline D26: Web Accessibility & 2 & 3 & 5 & 8 & 8 & 8 & 8 & 8 & 9 & 9 & 9 & 9 & 9 \\
\hline
\end{tabular}

Legend

Median without disagreement.

Median with disagreement: considering all ratings, at least one is a 1 , and at least one is a 9.

Figure 10. The final and user-evaluated TOPCOP taxonomy of patient portals.

\begin{tabular}{|c|c|c|c|c|c|c|c|}
\hline \multirow[t]{4}{*}{ ASPECTS } & \multirow{2}{*}{$\begin{array}{l}\text { DIMENSIONS } \\
\text { D1: Portal Type }\end{array}$} & \multicolumn{6}{|c|}{ CHARACTERISTICS } \\
\hline & & \multicolumn{3}{|c|}{ tethered } & \multicolumn{3}{|c|}{ integrated } \\
\hline & D2: Care Sector Target & primary care & $\sec$ & dary care & tertiary & & generic \\
\hline & D3: Patient Target & \multicolumn{3}{|c|}{ outpatient } & \multicolumn{3}{|c|}{ in \& outpatient } \\
\hline \multirow{5}{*}{ Portal Design } & D4: Portal Specialization & \multicolumn{2}{|l|}{ universal } & \multicolumn{2}{|c|}{ extended } & \multicolumn{2}{|c|}{ disease-specific } \\
\hline & D5: Medical Specialty & \multicolumn{3}{|c|}{ generic } & \multicolumn{3}{|c|}{ specialized } \\
\hline & D6: Web Accessibility & \multicolumn{3}{|c|}{ not supported } & \multicolumn{3}{|c|}{ supported } \\
\hline & D7: App Expandability & \multicolumn{3}{|c|}{ not expandable } & \multicolumn{3}{|c|}{ expandable } \\
\hline & D8: Activity Monitoring & \multicolumn{3}{|c|}{ no insight } & \multicolumn{3}{|c|}{ with insight } \\
\hline \multirow{3}{*}{ Management } & D9: Appointment Booking & no booking & \multicolumn{2}{|c|}{ request } & \multicolumn{2}{|c|}{ schedule } & hybrid \\
\hline & D10: Prescription Renewal & \multicolumn{3}{|c|}{ no renewal } & \multicolumn{3}{|c|}{ with renewal } \\
\hline & D11: Portal Customizability & \multicolumn{3}{|c|}{ not customizable } & \multicolumn{3}{|c|}{ customizable } \\
\hline \multirow{2}{*}{ Communication } & D12: E-Consult & no e-consult & \multicolumn{2}{|c|}{ asynchronous } & \multicolumn{2}{|c|}{ synchronous } & both \\
\hline & D13: System Notifications & no notifications & \multicolumn{2}{|c|}{ notifications } & \multicolumn{2}{|c|}{ reminder } & alerts \\
\hline \multirow{2}{*}{ Instruction } & D14: Patient Education & no educatio & & non-per & nalized & & rsonalized \\
\hline & D15: Therapy Instructions & no instructior & & non-prot & -based & & tocol-based \\
\hline & D16: Medication Summary & no su & $\mathrm{nm}$ & & & with & imary \\
\hline Self-Management & D17: Health Monitoring & no monitoring & & eported & self-trac & red & combined \\
\hline & D18: Visit Preparation & no pre & para & & & th $\mathrm{pr}$ & ration \\
\hline & D19: Declaration of Will & no rec & istra & & & ith re & ration \\
\hline Self-Determination & D20: Second Opinion & no ir & quir & & & with & uiry \\
\hline & D21: Study Sign-Up & nos & gn- & & & with & -up \\
\hline & D22: Record Access & no control & & sharec & ntrol & & Il control \\
\hline & D23: Records Management & no mar & $\overline{\text { lage }}$ & ent & & th $\mathrm{m}$ & gement \\
\hline Data ivianagementi & D24: Health Data Amend & review & & & & & delete \\
\hline & D25: Health Data Upload & no & ploc & & & with & $\mathrm{rad}$ \\
\hline
\end{tabular}




\section{Results of Round 4: Evaluation of the Final TOPCOP Taxonomy as a Whole}

In round 4, the panelists were asked to assess the general need for a taxonomy, the appropriateness of patient engagement as a guiding concept, and the TOPCOP taxonomy's usefulness related to its intended purpose. All 13 panelists participated in round 4.

In Figure 11, we present the evaluations' results for the research questions Q1, Q2, and Q4-Q9. Since group consensus was achieved without disagreement [99] for all research questions, no further interview round was launched.

Figure 11. Achieved consensus by all 13 panelists on the research questions Q1, Q2, Q4-Q9. The grey column shows the median without disagreement. p: patient.

\begin{tabular}{|c|c|c|c|}
\hline RESE & RAT & IIN & \\
\hline $\begin{array}{l}\text { Q1: How important do you consider the need for } \\
\text { a taxonomy for comparing p. portals? }\end{array}$ & $\begin{array}{llllll}6 & 6 & 7 & 7 & 7 & 8\end{array}$ & 8 & $\begin{array}{llllll}9 & 9 & 9 & 9 & 9 & 9\end{array}$ \\
\hline $\begin{array}{l}\text { Q2: How suitable do you consider patient engage- } \\
\text { ment as a guiding concept for comparing p. portals? }\end{array}$ & $\begin{array}{llllll}3 & 7 & 8 & 8 & 8 & 8\end{array}$ & 8 & $\begin{array}{llllll}8 & 8 & 8 & 8 & 9 & 9\end{array}$ \\
\hline $\begin{array}{l}\text { Q4: How understandable is the form and structure } \\
\text { of the final taxonomy? }\end{array}$ & $\begin{array}{llllll}4 & 7 & 7 & 7 & 8 & 8\end{array}$ & 8 & $\begin{array}{llllll}8 & 8 & 8 & 8 & 8 & 9\end{array}$ \\
\hline $\begin{array}{l}\text { Q5: How useful is the final taxonomy for classifying } \\
\text { p. portals following patient engagement? }\end{array}$ & $\begin{array}{llllll}7 & 7 & 7 & 7 & 7 & 7\end{array}$ & 8 & $\begin{array}{llllll}8 & 8 & 8 & 9 & 9 & 9\end{array}$ \\
\hline $\begin{array}{l}\text { Q6: How useful is the final taxonomy for comparing } \\
\text { p. portals following patient engagement? }\end{array}$ & $\mid \begin{array}{llllll}2 & 7 & 7 & 7 & 7 & 7\end{array}$ & 8 & $\begin{array}{llllll}8 & 8 & 8 & 8 & 9 & 9\end{array}$ \\
\hline $\begin{array}{l}\text { Q7: How useful is the final taxonomy for assisting } \\
\text { you in better understanding p. portals based on } \\
\text { characteristics supporting patient engagement? }\end{array}$ & $\begin{array}{llllll}3 & 6 & 6 & 7 & 7 & 7\end{array}$ & 7 & $\begin{array}{llllll}8 & 8 & 8 & 9 & 9 & 9\end{array}$ \\
\hline $\begin{array}{l}\text { Q8: How useful is the final taxonomy for creating } \\
\text { an initial requirement profile for p. portals based } \\
\text { on characteristics supporting patient engagement? }\end{array}$ & $\mid \begin{array}{llllll}6 & 7 & 7 & 7 & 7 & 7\end{array}$ & 8 & $\begin{array}{llllll}8 & 8 & 8 & 9 & 9 & 9\end{array}$ \\
\hline $\begin{array}{l}\text { Q9: How useful is the final taxonomy for selecting } \\
\text { p. portals offered on the market based on } \\
\text { characteristics supporting patient engagement? }\end{array}$ & $\begin{array}{llllll}6 & 7 & 7 & 7 & 8 & 8\end{array}$ & 8 & $\begin{array}{llllll}8 & 8 & 8 & 9 & 9 & 9\end{array}$ \\
\hline
\end{tabular}

The results shown in Figure 11 can be interpreted as follows. The panelists clearly agreed that there is a need for a taxonomy to distinguish among patient portals (median of 8 for Q1). Twelve panelists considered patient engagement to be an appropriate distinguishing concept for comparing patient portals (median of 8 for Q2). Only the panelist who assessed question Q2 with a rating of 3 proposed "System Architecture, Data
Types, and Interoperability" as a more appropriate concept for comparing patient portals. Further, the panelists were asked to propose alternative distinguishing concepts appropriate for comparing patient portals (Q3). Since research question Q3 was an open-ended question, it is not part of Figure 11. Therefore, we present the proposed alternative concepts in Table 3.

Table 3. Alternative distinguishing concepts proposed in round 4.

\begin{tabular}{ll}
\hline Proposed alternative distinguishing concepts (Q3) & $\begin{array}{l}\text { Number of panelists proposing an alterna- } \\
\text { tive distinguishing concept }\end{array}$ \\
\hline Comparison of patient portals based on characteristics promoting "Health Literacy" & 1 \\
Comparison of patient portals based on characteristics supporting "Improvement of Health Outcomes" & 1 \\
$\begin{array}{l}\text { Comparison of patient portals based on characteristics related to "System Architecture, Data Types, and } \\
\text { Interoperability" }\end{array}$ \\
$\begin{array}{l}\text { Comparison of patient portals based on characteristics related to "Improvement of Work Efficiency and } \\
\text { Cost Savings" }\end{array}$
\end{tabular}


We continued interpreting the results presented in Figure 11, which relate to the case study and the assessment of the taxonomy's usefulness. With a median of 8 , the panelists considered the form and structure of the final taxonomy to be understandable (Q4). However, 1 panelist who assessed Q4 with a rating of 4 argued that the taxonomy contains too many dimensions while, on the contrary, 1 panelist who assessed Q4 with a rating of 7 proposed refining the taxonomy with additional subcharacteristics to achieve a more accurate comparison of patient portals. All panelists considered the final taxonomy to be appropriate for classifying patient portals, giving ratings between 7 and 9 with a median of 8 (Q5). Further, they considered, with a median of 8 , the taxonomy to be appropriate for comparing patient portals (Q6) and appropriate for better understanding of patient portals based on characteristics supporting patient engagement (median 7 for Q7).
Since the TOPCOP taxonomy is also intended to help health information managers select patient portals offered on the market, the panelists were requested to assess its usefulness in this regard. With a median of 8 , the group consensus was achieved on both the taxonomy's usefulness for creating an initial requirement profile for patient portals (Q8) and selecting patient portals offered on the market based on characteristics supporting patient engagement (Q9). To sum up, by applying the TOPCOP taxonomy to compare 2 patient portals, we could indeed show that it is useful in contrasting and comparing patient portals from different vendors. In Figure 12, we show an example of a panelist's comparison. By marking each patient portal's characteristics, the differences and similarities of the 2 patient portals could be easily recognized.

Figure 12. Example of a comparison of 2 real patient portals carried out with the TOPCOP taxonomy by marking the respective characteristics.

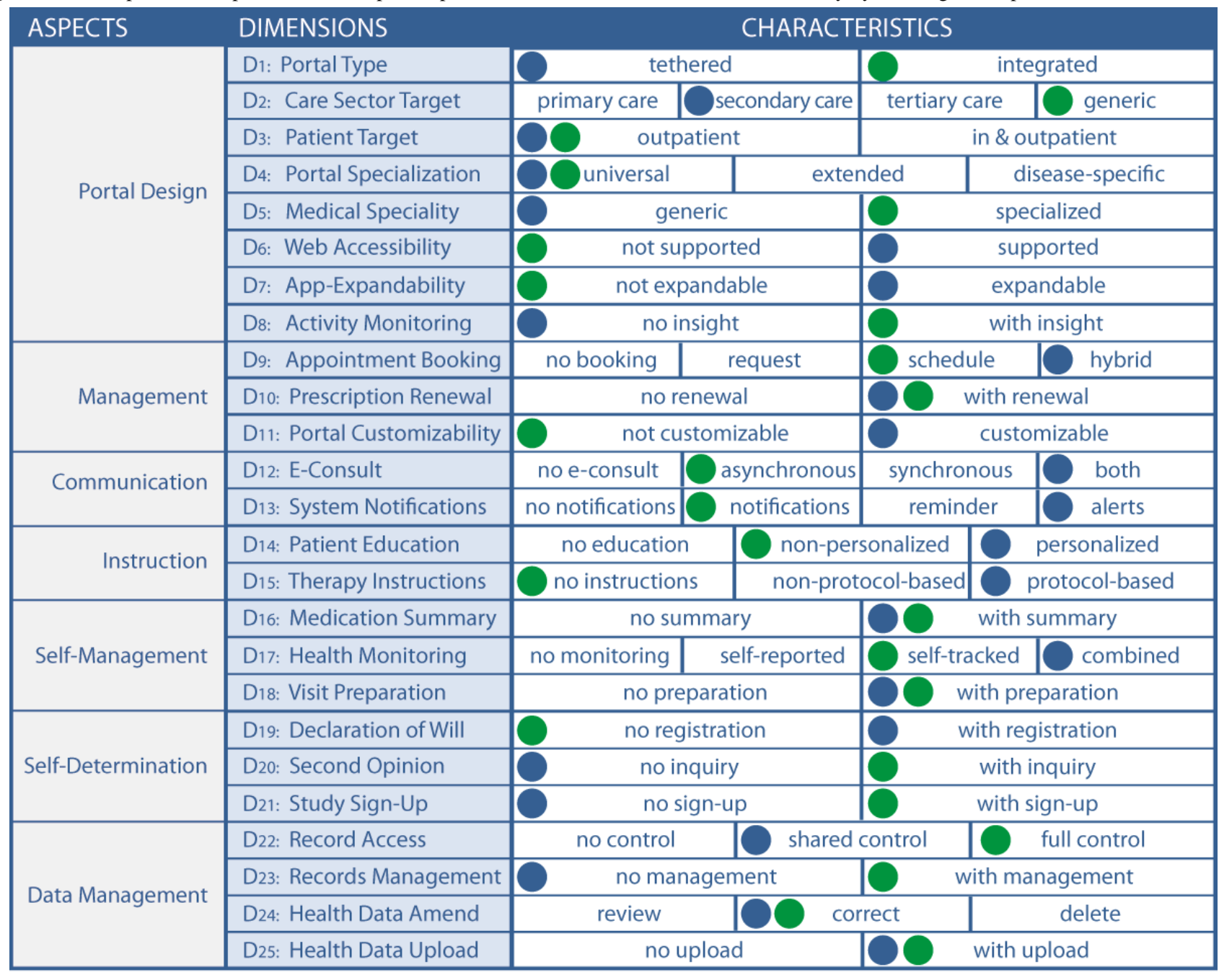

Legend

Patient portal 1

Patient portal 2

\section{Additional Findings: The Taxonomy-Evaluation-Delphi Approach (TED)}

Evaluation is a challenging, essential, and crucial component of the research process $[110,115]$. One criterion for assessing artifacts such as taxonomies is by evaluating their usefulness related to their intended purpose $[111,116]$. However, there are only very few taxonomy-specific evaluation guidelines [117], but multiple evaluation approaches can be applied in health informatics [118-120]. Szopinski et al [49] analyzed the various approaches researchers applied to evaluate taxonomies in the information system's domain and demonstrated that the Delphi technique was hardly used. Analyzing 61 evaluation approaches, they found just 1 study where the Delphi technique was used 
to evaluate the taxonomy [49]. In this study, panelists were asked to classify items into a deductively developed taxonomy and assess if the items were classified correctly [121]. In contrast, our modified Delphi approach aims to (1) first improve a conceptually and empirically created taxonomy [32] in multiple rounds by the users and (2) then evaluate the jointly created taxonomy by achieving users' consensus on the usefulness of the taxonomy. Therefore, the health information managers first compared the real-world patient portals with each other by performing a use case and then assessed the taxonomy related to its intended use. In Table 4, we describe the differences between the classic Delphi technique and our approach. The modified Delphi approach we used is, to the best of our knowledge, a new Delphi approach in health informatics for evaluating a taxonomy. We, therefore, call this approach the Taxonomy-Evaluation-Delphi (TED) approach.

Table 4. Comparison of the classic Delphi technique with the Taxonomy-Evaluation-Delphi (TED) approach.

\begin{tabular}{|c|c|c|}
\hline Criteria/Delphi & Classic Delphi & TED approach \\
\hline Objective & To make forecasts to plan ahead $[60,82]$ & $\begin{array}{l}\text { To collect new ideas to improve the taxonomy and to have the usefulness } \\
\text { of a conceptually and empirically created taxonomy evaluated by the in- } \\
\text { tended users }\end{array}$ \\
\hline Approach & $\begin{array}{l}\text { Obtain the most reliable consensus on the estima- } \\
\text { tion of numerical quantity [105] }\end{array}$ & $\begin{array}{l}\text { Obtain the most reliable consensus on the taxonomy's usefulness related } \\
\text { to its intended purpose guided by the user's needs }\end{array}$ \\
\hline Consensus metric & Median without dispersion & Median with dispersion based on the RAM ${ }^{\mathrm{a}}$ method [99] \\
\hline Panelists & $\begin{array}{l}\text { Experts }{ }^{b} \text { with a deep understanding of the issues } \\
\text { of concern [122] }\end{array}$ & $\begin{array}{l}\text { The taxonomy's users with different levels of experience and understanding } \\
\text { of the issue of concern }\end{array}$ \\
\hline Number of rounds & $\begin{array}{l}\text { Guided by the level of group consensus achieved } \\
{[75,76,94]}\end{array}$ & $\begin{array}{l}\text { Guided by elicitation of new evidence [95] and the level of group consensus } \\
\text { achieved }[75,76,94]\end{array}$ \\
\hline Procedure & Questionnaires and follow-up interviews [60] & $\begin{array}{l}\text { Introductory conversations, online questionnaires, and performing a case } \\
\text { study }\end{array}$ \\
\hline Outset & $\begin{array}{l}\text { Qualitative questions to collect initial knowledge } \\
\text { to create/refine the research subject [60] }\end{array}$ & $\begin{array}{l}\text { Quantitative questions to assess dimensions and characteristics, qualitative } \\
\text { questions to collect new ideas to improve the taxonomy, and a case study } \\
\text { to compare real patient portals as a basis for the taxonomy's evaluation }\end{array}$ \\
\hline Result & Agreement on numerical quantities [60] & Improved and evaluated useful taxonomy based on the users' needs \\
\hline
\end{tabular}

${ }^{a}$ RAM: RAND/UCLA Appropriateness Method.

${ }^{\mathrm{b}}$ There is ambiguity regarding the term expert concerning the Delphi technique as there is no unequivocal definition [82,96,123].

\section{Discussion}

\section{Principal Findings}

With this study, we were able to demonstrate that the need for a taxonomy to compare and classify patient portals exists among health information managers and that the concept of patient engagement to compare and select patient portals is considered appropriate.

Applying a modified Delphi approach, we improved the TOPCOP taxonomy based on the specific needs of the users. The final TOPCOP taxonomy consists of 25 dimensions with 65 characteristics, compared to 20 dimensions and 49 characteristics of the initial TOPCOP taxonomy.

We were able to demonstrate that the health information managers considered the final taxonomy to be useful in classifying and comparing patient portals. Further, we demonstrated that the final TOPCOP taxonomy supports the users in better understanding patient portals and assists them in selecting patient portals offered on the market. We were able to collect 4 alternative ideas on distinguishing concepts to compare patient portals that may serve for future research. As an additional outcome of our study, we created, to the best of our knowledge, a new Delphi approach in health informatics for evaluating a taxonomy.

\section{Comparison With Prior Work}

At present, there exists only a limited number of publications related to patient portal taxonomies. Ammenwerth et al [20] developed a taxonomy that aims to distinguish patient portals in a systematic review dealing with their effect on patient empowerment and health-related outcomes. Roehrs et al [124] developed a taxonomy that aims to identify open questions related to personal health record (PHR) data types, features, and architecture types. A PHR provides patients with web-based access to their health data that is under the control of the patient [124], while an EHR typically is under the control of the provider [7,19,22]. Fernández-Alemán et al [125] analyzed free web-based PHRs to identify their features and functions to better understand the PHR market. They created a framework of 4 dimensions intended to support patients in selecting a PHR that best fits their needs [125]. Scheplitz et al [126] created a framework for patient portal functionalities to record all possible functions to identify specification gaps related to software development. Walker et al [8] developed a framework to evaluate how well health information technology can support patient engagement by applying 5 engagement scoring levels. 
These attempts only provide part of a potential patient portal taxonomy and are developed for different users and purposes. Since the user determines the intended purpose of a taxonomy and the purpose guides the development by focusing on a specific phenomenon of interest, different users or purposes may lead to different taxonomies [46,51,55]. Further, a useful taxonomy must yield utility for a specific problem domain [58]. To sum up, the found taxonomies are not suitable to yield utility for health information managers for classifying and comparing patient portals based on characteristics appropriate for promoting patient engagement and understanding the differences and similarities. Therefore, the TOPCOP taxonomy was specifically developed for health information managers to compare and select patient portals offered on the market.

\section{Limitations}

Our approach to evaluating the TOPCOP taxonomy has some potential limitations.

First, panelists were selected from Germany, Austria, and Switzerland while the scope of the TOPCOP taxonomy is to support health information managers from any country. Since we were not able to attract participants from other countries, we aimed to assemble the panel as heterogeneously as possible, with different educational backgrounds and work experience, to achieve the best possible understanding of different viewpoints. Further, by selecting participants from 3 countries, we were able to map expertise from 3 different health care systems and integrate experiences with different levels of health care systems' digitization.

The second limitation relates to the panelists' experience with patient portals. Patient portals are not widely used in Germany, Austria, or Switzerland [32], and the experience with patient portals varied from little experience to much experience among the selected health information managers. Including participants with little experience with patient portals may lead to different results than if the participants had a deep understanding. As the taxonomy is not intended to only serve highly experienced but also inexperienced users, a composition of the panel that considers different levels of experience and understanding may increase the variety of viewpoints and the range of user needs related to the taxonomy. This variety may make the taxonomy even more useful [127].

The third limitation relates to the risk that the panelists may misunderstand what to evaluate. During the initial phone calls with potential participants, we noticed that some users assumed that the taxonomy's evaluation related to the suitability of functionalities for patient portals. However, the evaluation related to a dimension's appropriateness for classifying and comparing patient portals based on patient engagement. To ensure that there was no confusion, we explained the difference in individual introductory video conferences. Further, in the survey's introductory part, we outlined the scope of the evaluation and formulated the questionnaire's questions with unambiguous wording.

The fourth limitation is related to the Delphi technique itself. Delphi aims to obtain group consensus on opinions [68], but the achievement of consensus does not necessarily mean that the correct answer was found [84]. Besides, the composition of the panel may influence the research outcome [88,128]. To address these problems, we assembled the panel as heterogeneously as possible to integrate the broadest possible viewpoints and experience with patient portals. The selection of the panel was guided by the goal of achieving the best expertise available.

To determine the achievement of group consensus, we applied the RAND/UCLA concept appropriate for evaluation [101] and widely used to assess the appropriateness of health care services $[100,129]$. The survey was conducted anonymously to avoid the problem of dominant panelists possibly influencing individual opinions [102]. By applying all these measures, we believe that we were able to reduce any inherent bias in a possible method in the best way.

\section{Practical Implication}

The scope of the TOPCOP taxonomy is to serve health information managers with different degrees of knowledge related to patient portals and for various areas of application. The taxonomy may thus serve health information managers as a starting point to better understand the complex domain of patient portals since it describes the various aspects of patient portals. Further, 2 or more patient portals can be described by marking the respective characteristics. This shows the differences and similarities of the patient portals (Figure 12) and so supports the health information managers in classifying and comparing patient portals.

Since each health care institution may have different requirements related to a patient portal, the TOPCOP taxonomy can serve to create a requirement profile. By marking those characteristics in the taxonomy that best meet the needs of a health care institution, health information managers can create an initial requirement profile. This profile can then be used for a targeted search and selection of suitable portals offered on the market.

By providing a standardized terminology to describe various aspects of patient portals independent of clinical setting or country, the TOPCOP taxonomy is also useful for advancing research and evaluation of patient portals. It can, for example, be used to systematically describe patient portals as part of systematic reviews on their impact. The need for a taxonomy in this context has already been stressed in patient portal reviews [40].

\section{Conclusions}

The TOPCOP taxonomy aims to support health information managers in comparing and selecting patient portals. By providing a standardized terminology to describe various aspects of patient portals independent of clinical setting or country, the taxonomy will also be useful for advancing research and evaluation of patient portals. Since the health information managers contributed to the taxonomy's development, we were able to improve the taxonomy's quality and usefulness based on the users' needs.

The taxonomy consists of a manageable number of characteristics and dimensions and is therefore flexible for future 
changes. If needed, new dimensions can be added or removed according to future technological development. Further, due to its flexible form, the users can adjust the taxonomy to their personal needs. The initial TOPCOP taxonomy was developed by analyzing patient portals from 15 countries worldwide. It was then improved by health information managers with various degrees of patient portal experience from 3 countries with different levels of health care digitization. We, therefore, consider our taxonomy suitable to compare and classify patient portals from any country. The taxonomy may also contribute to the progress of health care digitization as it may enhance human resources capacity and effectiveness.

\section{Conflicts of Interest}

None declared.

\section{Multimedia Appendix 1}

Achieved consensus on existing dimensions after round 1 .

[PDF File (Adobe PDF File), $400 \mathrm{~KB}$-Multimedia Appendix 1]

\section{Multimedia Appendix 2}

Consensus on new characteristics and dimensions after round 2 presented to the panelists in round 3.

[PDF File (Adobe PDF File), 402 KB-Multimedia Appendix 2]

\section{Multimedia Appendix 3}

Presentation of a proposal of a new characteristic to refine an existing dimension.

[PDF File (Adobe PDF File), 284 KB-Multimedia Appendix 3]

\section{Multimedia Appendix 4}

A detailed description of dimensions and characteristics.

[PDF File (Adobe PDF File), 190 KB-Multimedia Appendix 4]

\section{References}

1. Beal LL, Kolman JM, Jones SL, Khleif A, Menser T. Quantifying Patient Portal Use: Systematic Review of Utilization Metrics. J Med Internet Res 2021 Feb 25;23(2):e23493 [FREE Full text] [doi: 10.2196/23493] [Medline: 33629962]

2. Nøst TH, Faxvaag A, Steinsbekk A. Participants' views and experiences from setting up a shared patient portal for primary and specialist health services- a qualitative study. BMC Health Serv Res 2021 Feb 24;21(171):2-9 [FREE Full text] [doi: 10.1186/s12913-021-06188-8] [Medline: 33627122]

3. Nazi KM, Turvey CL, Klein DM, Hogan TP. A Decade of Veteran Voices: Examining Patient Portal Enhancements Through the Lens of User-Centered Design. J Med Internet Res 2018 Jul 10;20(7):e10413 [FREE Full text] [doi: 10.2196/10413] [Medline: 29991468]

4. Wiljer D, Urowitz S, Apatu E, DeLenardo C, Eysenbach G, Harth T, et al. Patient accessible electronic health records: exploring recommendations for successful implementation strategies. J Med Internet Res 2008 Oct 31;10(4):e34 [FREE Full text] [doi: 10.2196/jmir.1061] [Medline: 18974036$]$

5. Vreugdenhil MMT, Ranke S, de Man Y, Haan MM, Kool RB. Patient and Health Care Provider Experiences With a Recently Introduced Patient Portal in an Academic Hospital in the Netherlands: Mixed Methods Study. J Med Internet Res 2019 Aug 20;21(8):13743 [FREE Full text] [doi: 10.2196/13743] [Medline: 31432782]

6. Stewart MT, Hogan TP, Nicklas J, Robinson SA, Purington CM, Miller CJ, et al. The Promise of Patient Portals for Individuals Living With Chronic Illness: Qualitative Study Identifying Pathways of Patient Engagement. J Med Internet Res 2020 Jul 17;22(7):e17744 [FREE Full text] [doi: 10.2196/17744] [Medline: $\underline{\text { 32706679] }}$

7. Crameri K, Maher L, Van Dam P, Prior S. Personal electronic healthcare records: What influences consumers to engage with their clinical data online? A literature review. Health Inf Manag 2020 Jan 10:1833358319895369. [doi: 10.1177/1833358319895369] [Medline: 31918578]

8. Walker DM, Sieck CJ, Menser T, Huerta TR, Scheck McAlearney A. Information technology to support patient engagement: where do we stand and where can we go? J Am Med Inform Assoc 2017 Nov 01;24(6):1088-1094 [FREE Full text] [doi: 10.1093/jamia/ocx043] [Medline: 28460042]

9. Wass S, Vimarlund V. The Role of PAEHRs in Patient Involvement. J Med Syst 2018 Sep 25;42(11):210 [FREE Full text] [doi: 10.1007/s10916-018-1070-y] [Medline: 30255404]

10. Tang PC, Ash JS, Bates DW, Overhage JM, Sands DZ. Personal Health Records: Definitions, Benefits, and Strategies for Overcoming Barriers to Adoption. Journal of the American Medical Informatics Association 2006 Mar 01;13(2):121-126 [FREE Full text] [doi: 10.1197/jamia.m2025] 
11. Irizarry T, DeVito Dabbs A, Curran CR. Patient Portals and Patient Engagement: A State of the Science Review. J Med Internet Res 2015 Jun 23;17(6):e148 [FREE Full text] [doi: 10.2196/jmir.4255] [Medline: 26104044]

12. Bouayad L, Ialynytchev A, Padmanabhan B. Patient Health Record Systems Scope and Functionalities: Literature Review and Future Directions. J Med Internet Res 2017 Nov 15;19(11):e388 [FREE Full text] [doi: 10.2196/jmir.8073] [Medline: 29141839]

13. Barbarito F, Pinciroli F, Barone A, Pizzo F, Ranza R, Mason J, et al. Implementing the lifelong personal health record in a regionalised health information system: the case of Lombardy, Italy. Comput Biol Med 2015 Apr;59:164-174. [doi: 10.1016/j.compbiomed.2013.10.021] [Medline: 24238969]

14. Risling T, Martinez J, Young J, Thorp-Froslie N. Evaluating Patient Empowerment in Association With eHealth Technology: Scoping Review. J Med Internet Res 2017 Sep 29;19(9):e329 [FREE Full text] [doi: 10.2196/jmir.7809] [Medline: 28963090]

15. Mossaed S, Leonard K, Eysenbach G. Patient Preferences and Perspectives on Accessing Their Medical Records. J Med Imaging Radiat Sci 2015 Jun;46(2):205-214. [doi: 10.1016/j.jmir.2014.11.001] [Medline: 31052095]

16. Prokosch H, Schüttler C, Schraudt M, Öfelein M, Maier C. Digital Patient Communication: Improving the Hospital-Patient Relationship. Stud Health Technol Inform 2019;259:3-9. [doi: 10.3233/978-1-61499-961-4-3] [Medline: 30923263]

17. Ammenwerth E, Schnell-Inderst P, Hoerbst A. The impact of electronic patient portals on patient care: a systematic review of controlled trials. J Med Internet Res 2012 Nov 26;14(6):e162 [FREE Full text] [doi: 10.2196/jmir.2238] [Medline: 23183044]

18. Pinciroli F, Corso M, Fuggetta A, Masseroli M, Bonacina S, Marceglia S. Telemedicine and E-Health. IEEE Pulse 2011 May;2(3):62-70. [doi: 10.1109/mpul.2011.941524]

19. Tsai C, Eghdam A, Davoody N, Wright G, Flowerday S, Koch S. Effects of Electronic Health Record Implementation and Barriers to Adoption and Use: A Scoping Review and Qualitative Analysis of the Content. Life (Basel) 2020 Dec 04;10(12):A [FREE Full text] [doi: 10.3390/life10120327] [Medline: 33291615]

20. Ammenwerth E, Hoerbst A, Lannig S, Mueller G, Siebert U, Schnell-Inderst P. Effects of Adult Patient Portals on Patient Empowerment and Health-Related Outcomes: A Systematic Review. Stud Health Technol Inform 2019 Aug 21;264:1106-1110. [doi: 10.3233/SHTI190397] [Medline: 31438096]

21. Schaller M, Dornauer V, Hackl W, Lechleitner G, Überegger M, Ammenwerth E. Implementing National Electronic Health Records in Nursing Homes in Tyrol: A Nursing Management Perspective. Stud Health Technol Inform 2020 Jun 23;271:240-247. [doi: 10.3233/SHTI200102] [Medline: 32578569]

22. Rigby M, Georgiou A, Hyppönen H, Ammenwerth E, de Keizer N, Magrabi F, et al. Patient Portals as a Means of Information and Communication Technology Support to Patient- Centric Care Coordination - the Missing Evidence and the Challenges of Evaluation. A joint contribution of IMIA WG EVAL and EFMI WG EVAL. Yearb Med Inform 2015 Aug 13;10(1):148-159 [FREE Full text] [doi: 10.15265/IY-2015-007] [Medline: 26123909]

23. McCoy AB, Wright A, Eysenbach G, Malin BA, Patterson ES, Xu H, et al. State of the Art in Clinical Informatics: Evidence and Examples. Yearb Med Inform 2013 Mar 05;22(01):13-19. [doi: 10.1055/s-0038-1638827]

24. Ammenwerth E, Lannig S, Hörbst A, Mueller G, Schnell-Inderst P. Adult patient access to electronic health records. Cochrane Database Syst Rev 2017 Jul 27;6:CD012707 [FREE Full text] [doi: 10.1002/14651858.CD012707]

25. Alturkistani A, Greenfield G, Greaves F, Aliabadi S, Jenkins RH, Costelloe C. Patient Portal Functionalities and Uptake: Systematic Review Protocol. JMIR Res Protoc 2020 Jul 31;9(7):e14975. [doi: 10.2196/14975]

26. Nguyen OT, Alishahi Tabriz A, Huo J, Hanna K, Shea CM, Turner K. Impact of Asynchronous Electronic Communication-Based Visits on Clinical Outcomes and Health Care Delivery: Systematic Review. J Med Internet Res 2021 May 05;23(5):e27531 [FREE Full text] [doi: 10.2196/27531] [Medline: $\underline{\text { 33843592] }}$

27. Otte-Trojel T, de Bont A, Rundall TG, van de Klundert J. What do we know about developing patient portals? a systematic literature review. J Am Med Inform Assoc 2016 Apr;23(e1):e162-e168 [FREE Full text] [doi: 10.1093/jamia/ocv114] [Medline: 26335985]

28. Nøhr C, Parv L, Kink P, Cummings E, Almond H, Nørgaard JR, et al. Nationwide citizen access to their health data: analysing and comparing experiences in Denmark, Estonia and Australia. BMC Health Serv Res 2017 Aug 07;17(1):534 [FREE Full text] [doi: 10.1186/s12913-017-2482-y] [Medline: 28784173]

29. Tavares J, Oliveira T. New Integrated Model Approach to Understand the Factors That Drive Electronic Health Record Portal Adoption: Cross-Sectional National Survey. J Med Internet Res 2018 Nov 19;20(11):e11032 [FREE Full text] [doi: 10.2196/11032] [Medline: 30455169]

30. Archer N, Fevrier-Thomas U, Lokker C, McKibbon KA, Straus SE. Personal health records: a scoping review. J Am Med Inform Assoc 2011;18(4):515-522 [FREE Full text] [doi: 10.1136/amiajnl-2011-000105] [Medline: 21672914]

31. Global diffusion of eHealth: making universal health coverage achievable: report of the third global survey on eHealth. World Health Organization. 2016 Dec 15. URL: https://www.who.int/publications/i/item/9789241511780 [accessed 2021-01-17]

32. Glöggler M, Ammenwerth E. Development and Validation of a Useful Taxonomy of Patient Portals Based on Characteristics of Patient Engagement. Methods Inf Med 2021 Jun 09;60(S 01):e44-e55 [FREE Full text] [doi: 10.1055/s-0041-1730284] [Medline: 34243191] 
33. Ammenwerth E, Duftschmid G, Al-Hamdan Z, Bawadi H, Cheung NT, Cho K, et al. International Comparison of Six Basic eHealth Indicators Across 14 Countries: An eHealth Benchmarking Study. Methods Inf Med 2020 Dec;59(S 02):e46-e63 [FREE Full text] [doi: 10.1055/s-0040-1715796] [Medline: 33207386]

34. Lupiáñez-Villanueva F, Folkvord F, Faulí F, Altenhofer M, Hocking L, Harshfield A. Benchmarking deployment of eHealth among general practitioners - Final Report. Publications Office of the European Union. Luxembourg: European Union; 2018. URL: https://op.europa.eu/en/publication-detail/-/publication/d1286ce7-5c05-11e9-9c52-01aa75ed71a1 [accessed 2021-03-05]

35. Wildenbos GA, Horenberg F, Jaspers M, Peute L, Sent D. How do patients value and prioritize patient portal functionalities and usage factors? A conjoint analysis study with chronically ill patients. BMC Med Inform Decis Mak 2018 Nov 21;18(1):108 [FREE Full text] [doi: 10.1186/s12911-018-0708-5] [Medline: 30463613]

36. Shimada SL, Allison JJ, Rosen AK, Feng H, Houston TK. Sustained Use of Patient Portal Features and Improvements in Diabetes Physiological Measures. J Med Internet Res 2016 Jul 01;18(7):e179 [FREE Full text] [doi: 10.2196/jmir.5663] [Medline: 27369696]

37. Hazara AM, Durrans K, Bhandari S. The role of patient portals in enhancing self-care in patients with renal conditions. Clin Kidney J 2020 Feb;13(1):1-7 [FREE Full text] [doi: 10.1093/ckj/sfz154] [Medline: 32082547]

38. What do Health Information Managers Do? University of Wisconsin Health Information Management \& Technology. 2021. URL: https://himt.wisconsin.edu/about-himt/what-him-managers-do/ [accessed 2021-02-20]

39. Bates M, Black C, Blair F, Davis L, Ingram S, Lane D, et al. Perceptions of health information management educational and practice experiences. Perspect Health Inf Manag 2014;11:1d [FREE Full text] [Medline: 25214821]

40. Ammenwerth E, Neyer S, Hörbst A, Mueller G, Siebert U, Schnell-Inderst P. Adult patient access to electronic health records. Cochrane Database Syst Rev 2021 Feb 26;2:CD012707. [doi: 10.1002/14651858.CD012707.pub2] [Medline: 33634854]

41. Ammenwerth E. Die Bewertung von Informationssystemen des Gesundheitswesens: Beiträge für ein umfassendes Informationsmanagement (UMIT-Schriftenreihe). Düren, Germany: Shaker Verlag; Sep 01, 2004.

42. Doty DH, Glick WH. Typologies As a Unique Form Of Theory Building: Toward Improved Understanding and Modeling. Acad Manag Rev 1994 Apr 01;19(2):230-251. [doi: 10.5465/amr.1994.9410210748]

43. Leiner F, Gaus W, Haux R, Knaup-Gregori P, editors. Medical Data Management: A Practical Guide, 1st edition. New York, NY: Springer Verlag; 2003:204.

44. Bailey KD. Typologies and Taxonomies: An Introduction to Classification Techniques. Thousand Oaks, CA: SAGE Publications, Inc; 1994:89.

45. Mrosek R, Dehling T, Sunyaev A. Taxonomy of health IT and medication adherence. Health Policy and Technology 2015 Sep;4(3):215-224. [doi: 10.1016/j.hlpt.2015.04.003]

46. Glass RL, Vessey I. Contemporary application-domain taxonomies. IEEE Softw 1995 Jul;12(4):63-76. [doi: 10.1109/52.391837]

47. Vegas S, Juristo N, Basili V. Maturing Software Engineering Knowledge through Classifications: A Case Study on Unit Testing Techniques. IIEEE Trans. Software Eng 2009 Jul;35(4):551-565. [doi: 10.1109/TSE.2009.13]

48. Bailey B, Martin G, Anderson T, editors. Taxonomies for the Development and Verification of Digital Systems. New York, NY: Springer US; 2005:180.

49. Szopinski D, Schoormann T, Kundisch D. Because your taxonomy is worth it: Towards a framework for taxonomy evaluation. 2019 Presented at: 27th European Conference on Information Systems (ECIS); June 8-14, 2019; Stock Uppsala, Sweden.

50. Lambe P. Organising Knowledge: Taxonomies, Knowledge and Organisational Effectiveness, 1st edition. Oxford, England: Chandos Publishing; Feb 28, 2007.

51. Nickerson RC, Varshney U, Muntermann J. A method for taxonomy development and its application in information systems. European Journal of Information Systems 2013;22(3):336-359 published online 19 June 2012. [doi: 10.1057/ejis.2012.26]

52. Remane G, Nickerson R, Hanelt A, Tesch J, Kolbe L. A Taxonomy of Carsharing Business Models. 2016 Presented at: 37th International Conference on Information Systems (ICIS); December 11-14, 2016; Dublin, Ireland.

53. De Los Reyes Arguelles E, Martinez-Goss M. Classical Taxonomy. Methods Microalgal Stud. Los Baños, Philippines: Philippine Science Letters and University of the Philippines Los Baños; Dec 2020:145-153.

54. Kwasnik BH. The Role of Classification in Knowledge Representation and Discovery. Library Trends 1999;48(1):22-47.

55. Nickerson RC, Varshney U, Muntermann J, Issac H. Taxonomy Development in Information Systems: Developing A Taxonomy Of Mobile Applications. Working Papers halshs-00375103. 2009. URL: https://ideas.repec.org/p/hal/wpaper/ halshs-00375103.html [accessed 2020-07-15]

56. March ST, Smith GF. Design and natural science research on information technology. Decision Support Systems 1995 Dec;15(4):251-266. [doi: 10.1016/0167-9236(94)00041-2]

57. Venable J. A framework for Design Science research activities. In: 2006 Information Resources Management Association International Conference. Washington, DC: Idea Group Publishing; 2006.

58. Hevner AR, March ST, Park J, Ram S. Design Science in Information Systems Research. MIS Quarterly 2004;28(1):75-105. [doi: $\underline{10.2307 / 25148625]}$ 
59. Peffers K, Tuunanen T, Rothenberger MA, Chatterjee S. A Design Science Research Methodology for Information Systems Research. Journal of Management Information Systems 2007;24(3):45-78. [doi: 10.2753/MIS0742-1222240302]

60. Dalkey N, Helmer O. An Experimental Application of the DELPHI Method to the Use of Experts. Management Science 1963 Apr;9(3):458-467. [doi: 10.1287/mnsc.9.3.458]

61. Strasser A. Delphi Method Variants in Information Systems Research: Taxonomy Development and Application. The Electronic Journal of Business Research Methods 2017;15(2):120-133 ISSN 1477-7029.

62. DeMuro PR, Ash J, Middleton B, Fletcher J, Madison CJ. A Quality, Benefit, Cost, and Financial Framework for Health Information Technology, E-Prescribing: A Delphi Study. Stud Health Technol Inform 2017;241:69-75 [FREE Full text] [doi: 10.3233/978-1-61499-794-8-69] [Medline: 28809185]

63. Brender J, Ammenwerth E, Nykänen P, Talmon J. Factors Influencing Success and Failure of Health Informatics Systems. Methods Inf Med 2006 Feb 06;45(1):125-136. [doi: 10.1055/s-0038-1634049]

64. Brender J, Nøhr C, McNair P. Research needs and priorities in Health Informatics - early results of a Delphi Study. In: Studies in Health Technology and Informatics. Amsterdam: IOS Press; 1999:191-196.

65. Nelson R, Staggers N. Health Informatics: An Interprofessional Approach. St. Louis, MI: Elsevier; Mar 31, $2015: 678$.

66. Fusfeld AR. Research Program on the Management of Science and Technology: The Delphi Technique, Survey and Comment. Cambridge, MA: Massachusetts Institute of Technology; Mar 1971.

67. Iivari J, Venable J. Action research and design science research - Seemingly similar but decisively dissimilar. : ECIS 2009 Proceedings. 73; 2009 Presented at: 17th European Conference on Information Systems (ECIS 2009); 2009; Verona, Italy URL: https://aisel.aisnet.org/ecis2009/73/

68. Flanagan T, Ashmore R, Banks D, MacInnes D. The Delphi method: Methodological issues arising from a study examining factors influencing the publication or non-publication of mental health nursing research. Mental Health Review Journal 2016 Jun 13;21(2):85-94. [doi: 10.1108/MHRJ-07-2015-0020]

69. Hanson CL, Oliver EJ, Dodd-Reynolds CJ, Pearsons A, Kelly P. A modified Delphi study to gain consensus for a taxonomy to report and classify physical activity referral schemes (PARS). Int J Behav Nutr Phys Act 2020 Dec 02;17(1):158 [FREE Full text] [doi: 10.1186/s12966-020-01050-2] [Medline: 33267840]

70. Ben-Chetrit E, Gattorno M, Gul A, Kastner DL, Lachmann HJ, Touitou I, et al. Consensus proposal for taxonomy and definition of the autoinflammatory diseases (AIDs): a Delphi study. Ann Rheum Dis 2018 Nov 12;77(11):1558-1565. [doi: 10.1136/annrheumdis-2017-212515] [Medline: 30100561]

71. Shoemaker LL, Lenker JA, Fuhrer MJ, Jutai JW, Demers L, DeRuyter F. Development and evaluation of a new taxonomy of mobility-related assistive technology devices. Am J Phys Med Rehabil 2010 Oct;89(10):795-808. [doi: 10.1097/PHM.0b013e3181f1bbcd] [Medline: 20855980]

72. Valentijn PP, Boesveld IC, van der Klauw DM, Ruwaard D, Struijs JN, Molema JJW, et al. Towards a taxonomy for integrated care: a mixed-methods study. Int J Integr Care 2015 Mar 04;15(1):e003 [FREE Full text] [doi: 10.5334/ijic.1513] [Medline: 25759607]

73. Chastin SFM, Schwarz U, Skelton DA. Development of a consensus taxonomy of sedentary behaviors (SIT): report of Delphi Round 1. PLoS One 2013 Dec 2;8(12):e82313 [FREE Full text] [doi: 10.1371/journal.pone.0082313] [Medline: 24312653]

74. Iqbal S, Pipon-Young L. The Delphi method. The Psychologist 2009;22(7):598-601.

75. Fink-Hafner D, Dagen T, Doušak M, Novak M, Hafner-Fink M. Delphi Method: Strengths and Weaknesses. Metodoloski zvezki 2019;16(2):1-19.

76. Linstone HA, Turoff M. The Delphi method : techniques and applications, 1st edition. Boston, MA: Addison-Wesley; 1975.

77. Donohoe HM, Needham RD. Moving best practice forward: Delphi characteristics, advantages, potential problems, and solutions. Int. J. Tourism Res 2009 Sep;11(5):415-437. [doi: 10.1002/jtr.709]

78. Erffmeyer RC, Erffmeyer ES, Lane IM. The Delphi Technique: An Empirical Evaluation of the Optimal Number of Rounds. Group \& Organization Studies 1986 Mar;11(1-2):120-128. [doi: 10.1177/105960118601100110]

79. Hasson F, Keeney S. Enhancing rigour in the Delphi technique research. Technological Forecasting and Social Change 2011 Nov;78(9):1695-1704. [doi: 10.1016/j.techfore.2011.04.005]

80. Quyên DTN. Developing University Governance Indicators and their Weighting System Using a Modified Delphi Method. Procedia - Social and Behavioral Sciences 2014 Aug;141:828-833. [doi: 10.1016/j.sbspro.2014.05.144]

81. Erffmeyer RC. Decision-Making Formats: a Comparison on an Evaluative Task of Interacting Groups, Consensus Groups, the Nominal Group Technique, and the Delphi Technique. Louisiana State University. 1981. URL: https://core.ac.uk/ download/pdf/217386485.pdf [accessed 2020-12-14]

82. du Plessis E, Human SP. The art of the Delphi technique: highlighting its scientific merit. Health SA Gesondheid 2007 Nov 17;12(4):a268. [doi: 10.4102/hsag.v12i4.268]

83. Hsu CC, Sandford BA. The Delphi Technique: Making Sense of Consensus. Pract Assessment, Research, and Evaluation 2007;12(10):1-8 [FREE Full text] [doi: 10.7275/pdz9-th90]

84. Hasson F, Keeney S, McKenna H. Research guidelines for the Delphi survey technique. J Adv Nurs 2000;32(4):1008-1015. [doi: 10.1046/j.1365-2648.2000.t01-1-01567.x] 
85. Goluchowicz K, Blind K. Identification of future fields of standardisation: An explorative application of the Delphi methodology. Technological Forecasting and Social Change 2011 Nov;78(9):1526-1541. [doi: 10.1016/j.techfore.2011.04.014]

86. Baker JA, Lovell K, Harris N, Campbell M. Multidisciplinary consensus of best practice for pro re nata (PRN) psychotropic medications within acute mental health settings: a Delphi study. J Psychiatr Ment Health Nurs 2007 Aug;14(5):478-484. [doi: 10.1111/j.1365-2850.2007.01112.x] [Medline: 17635256]

87. Skulmoski GJ, Hartman FT, Krahn J. The Delphi Method for Graduate Research. JITE:Research 2007;6:001-021. [doi: $10.28945 / 199]$

88. Avella JR. Delphi Panels: Research Design, Procedures, Advantages, and Challenges. IJDS 2016;11:305-321. [doi: $\underline{10.28945 / 3561]}$

89. Brook RH, Chassin MR, Fink A, Solomon DH, Kosecoff J, Park RE. A method for the detailed assessment of the appropriateness of medical technologies. Int J Technol Assess Health Care 1986 Mar 10;2(1):53-63. [doi: 10.1017/s0266462300002774] [Medline: 10300718]

90. McMillan SS, King M, Tully MP. How to use the nominal group and Delphi techniques. Int J Clin Pharm 2016 Jun 5;38(3):655-662 [FREE Full text] [doi: 10.1007/s11096-016-0257-x] [Medline: 26846316]

91. Choi BCK, Pak AWP. A catalog of biases in questionnaires. Prev Chronic Dis 2005 Jan;2(1):A13 [FREE Full text] [Medline: 15670466]

92. Boulkedid R, Abdoul H, Loustau M, Sibony O, Alberti C. Using and reporting the Delphi method for selecting healthcare quality indicators: a systematic review. PLoS One 2011 Jun 9;6(6):e20476 [FREE Full text] [doi: 10.1371/journal.pone.0020476] [Medline: 21694759]

93. Penna A, Grilli R, Filardo G, Mainini F, Zola P, Mantovani L, et al. Do different physicians' panels reach similar conclusions? A case study on practice guidelines for limited surgery in breast cancer. The European Journal of Public Health 1997 Dec 01;7(4):436-440. [doi: 10.1093/eurpub/7.4.436]

94. Akins RB, Tolson H, Cole BR. Stability of response characteristics of a Delphi panel: application of bootstrap data expansion. BMC Med Res Methodol 2005 Dec 01;5(1):37 [FREE Full text] [doi: 10.1186/1471-2288-5-37] [Medline: 16321161]

95. Wiliam D, Black P. Meanings and Consequences: a basis for distinguishing formative and summative functions of assessment? British Educational Research Journal 1996 Dec;22(5):537-548. [doi: 10.1080/0141192960220502]

96. Alarabiat A, Ramos I. The Delphi Method in Information Systems Research (2004-2017). EJBRM 2019 Jun 01;17(2):86-99. [doi: 10.34190/jbrm.17.2.04]

97. Schmidt R, Lyytinen K, Keil M, Cule P. Identifying Software Project Risks: An International Delphi Study. Journal of Management Information Systems 2001;17(4):5-36. [doi: 10.1080/07421222.2001.11045662]

98. Goodarzi Z, Abbasi E, Farhadian H. Achieving Consensus Deal with Methodological Issues in the Delphi Technique. International Journal of Agriculture Management and Development 2018;8(2):219-230. [doi: 10.22004/ag.econ.292533]

99. Fitch K, Bernstein SJ, Aguilar MD, Burnand B, LaCalle JR, Lázaro P, et al. The RAND/UCLA Appropriateness Method User's Manual. Santa Monica, CA: RAND Corporation; 2001:109.

100. Sanmartin C, Murphy K, Choptain N, Conner-Spady B, McLaren L, Bohm E, et al. Appropriateness of healthcare interventions: Concepts and scoping of the published literature. Int J Technol Assess Health Care 2008 Jul 4;24(03):342-349. [doi: $10.1017 / \mathrm{s} 0266462308080458$ ]

101. Santori G, Fontana I, Valente R, Ghirelli R, Valente U. Application of the RAND/UCLA Appropriateness Method to evaluate an information system for kidney/pancreas transplantation in adult recipients. Transplant Proc 2008 Jul;40(6):2021-2023. [doi: 10.1016/j.transproceed.2008.05.018] [Medline: 18675119]

102. Keeney S, Hasson F, McKenna HP. A critical review of the Delphi technique as a research methodology for nursing. International Journal of Nursing Studies 2001 Apr;38(2):195-200. [doi: 10.1016/s0020-7489(00)00044-4]

103. Kuusi O. Expertise in the future use of generic technologies: Epistemic and methodological considerations concerning Delphi studies (Acta Universitatis Oeconomicae Helsingiensis). Helsinki, Finland: Helsinki School of Economics and Business Administration; Jan 01, 1999:268.

104. Rowe G, Wright G. The Delphi technique as a forecasting tool: issues and analysis. International Journal of Forecasting 1999 Oct;15(4):353-375. [doi: 10.1016/S0169-2070(99)00018-7]

105. Dalkey NC. In: Dalkey NC, Rourke DL, Lewis R, Snyder D, editors. Studies in the quality of life: Delphi and decision-making. Lexington, MA: Lexington Books; Jan 01, 1972:161.

106. Daniel E, White A. The future of inter-organisational system linkages: findings of an international Delphi study. European Journal of Information Systems 2005;14(2):188-203. [doi: 10.1057/palgrave.ejis.3000529]

107. Video Conferencing, Cloud Phone, Webinars, Chat, Virtual Events. San Jose, California: Zoom Video Commun Inc URL: https://zoom.us/ [accessed 2020-12-11]

108. Online Umfrage erstellen. Switzerland: enuvo GmbH URL: https://www.umfrageonline.com/ [accessed 2021-01-20]

109. Dylan W. Integrating formative and summative functions of assessment. 2000 Presented at: Working Group 10 of the International Congress on Mathematics Education; July 31-August 6, 2000; Makuhari, Japan.

110. Bürkle T, Ammenwerth E, Prokosch H, Dudeck J. Evaluation of clinical information systems. What can be evaluated and what cannot? J Eval Clin Pract 2001 Nov;7(4):373-385. [doi: 10.1046/j.1365-2753.2001.00291.x] [Medline: 11737529] 
111. Venable J, Pries-Heje J, Baskerville R. FEDS: a Framework for Evaluation in Design Science Research. European Journal of Information Systems 2016;25:77-89. [doi: 10.1057/ejis.2014.36]

112. Creswell JW, Creswell JD. Research Design: Qualitative, Quantitative and Mixed Methods Approaches, 5th edition. Los Angeles, CA: Sage Publications, Inc; Jan 02, 2018:304.

113. Mayring P. Qualitative Inhaltsanalyse: Grundlagen und Techniken, 12th edition. Weinheim and Basel: Beltz Verlag; 2015:152.

114. Mayring P. Einführung in die qualitative Sozialforschung, 6th edition. Weinheim and Basel: Beltz Verlag; $2016: 170$.

115. Tsai C, Koch S. Towards a Framework for National eHealth Evaluation and Monitoring: A Combined Top-Down and Bottom-Up Approach Using Sweden as Example. Stud Health Technol Inform 2019 Aug 21;264:954-958. [doi: 10.3233/SHTI190365] [Medline: 31438065]

116. Piirainen K, Gonzalez R. Seeking Constructive Synergy: Design Science and the Constructive Research Approach. In: vom Brocke J, Hekkala R, Ram S, Rossi M, editors. Design Science at the Intersection of Physical and Virtual Design. DESRIST 2013. Lecture Notes in Computer Science, vol 7939. Berlin, Heidelberg: Springer; 2013:59-72.

117. Szopinski D, Schoormann T, Kundisch D. Criteria as a Prelude for Guiding Taxonomy Evaluation. 2000 Presented at: 53rd Annual Hawaii International Conference on System Sciences; January 7-10, 2020; Wailea, Maui, HI. [doi: 10.24251/hicss.2020.622]

118. Nykänen P, Kaipio J. Quality of health IT evaluations. In: Ammenwerth E, Rigby M, editors. Evidence-Based Health Informatics. Amsterdam, Netherlands: IOS Press BV; 2016:291-303.

119. Ammenwerth E, Brender J, Nykänen P, Prokosch H, Rigby M, Talmon J. Visions and strategies to improve evaluation of health information systems. Reflections and lessons based on the HIS-EVAL workshop in Innsbruck. Int J Med Inform 2004 Jun 30;73(6):479-491. [doi: 10.1016/j.ijmedinf.2004.04.004] [Medline: 15171977]

120. Kitsiou S, Manthou V, Vlachopoulou M. A Framework for the Evaluation of Integration Technology Approaches in Healthcare. 2006 Presented at: The Fifth International Conference on Biological Information and Biomedical Engineering; October 2006; Ioannina - Epirus, Greece.

121. Nambisan S, Agarwal R, Tanniru M. Organizational Mechanisms for Enhancing User Innovation in Information Technology. MIS Quarterly 1999 Sep;23(3):365-395. [doi: $10.2307 / 249468]$

122. Paraskevas A, Saunders MN. Beyond consensus: an alternative use of Delphi enquiry in hospitality research. Int J Contemp Hospitality Mngt 2012 Aug 17;24(6):907-924. [doi: 10.1108/09596111211247236]

123. Hussler C, Muller P, Rondé P. Is diversity in Delphi panelist groups useful? Evidence from a French forecasting exercise on the future of nuclear energy. Technological Forecasting and Social Change 2011 Nov;78(9):1642-1653. [doi: 10.1016/j.techfore.2011.07.008]

124. Roehrs A, da Costa CA, da Rosa Righi R, Farias De Oliveira KS. Personal Health Records: A Systematic Literature Review. J Med Internet Res 2017 Jan 06;19(1):e13 [FREE Full text] [doi: 10.2196/jmir.5876] [Medline: 28062391]

125. Fernández-Alemán JL, Seva-Llor CL, Toval A, Ouhbi S, Fernández-Luque L. Free Web-based personal health records: an analysis of functionality. J Med Syst 2013 Dec 13;37(6):9990. [doi: 10.1007/s10916-013-9990-z] [Medline: 24221916]

126. Scheplitz T, Benedict M, Esswein W. Patientenkompetenz durch Online-Portale - Eine Funktionsanalyse. 2018 Presented at: Multikonferenz Wirtschaftsinformatik (MKWI 2018); March 06-09, 2018; Lüneburg, Germany p. 744-755.

127. Rowe G, Wright G. The Delphi technique: Past, present, and future prospects — Introduction to the special issue. Technological Forecasting and Social Change 2011 Nov;78(9):1487-1490. [doi: 10.1016/j.techfore.2011.09.002]

128. Powell C. The Delphi technique: myths and realities. J Adv Nurs 2003 Feb;41(4):376-382. [doi: 10.1046/j.1365-2648.2003.02537.x] [Medline: 12581103 ]

129. Bell BG, Spencer R, Avery AJ, Campbell SM. Tools for measuring patient safety in primary care settings using the RAND/UCLA appropriateness method. BMC Fam Pract 2014 Jun 05;15(110):1-7 [FREE Full text] [doi: 10.1186/1471-2296-15-110] [Medline: 24902490]

\section{Abbreviations}

EHR: electronic health record

PHR: personal health record

RAM: RAND/UCLA Appropriateness Method

TED: Taxonomy-Evaluation-Delphi approach.

TOPCOP: Useful Taxonomy of Patient Portals based on Characteristics of Patient Engagement 
Edited by G Eysenbach; submitted 25.05.21; peer-reviewed by M Lotto, S Hajesmaeel Gohari, L Chirchir; comments to author 15.06.21; revised version received 15.07.21; accepted 31.07.21; published 05.10.21

Please cite as:

Glöggler M, Ammenwerth E

Improvement and Evaluation of the TOPCOP Taxonomy of Patient Portals: Taxonomy-Evaluation-Delphi (TED) Approach

J Med Internet Res 2021;23(10):e30701

URL: https://www.jmir.org/2021/10/e30701

doi: $10.2196 / 30701$

PMID: 34403354

CMichael Glöggler, Elske Ammenwerth. Originally published in the Journal of Medical Internet Research (https://www.jmir.org), 05.10.2021. This is an open-access article distributed under the terms of the Creative Commons Attribution License (https://creativecommons.org/licenses/by/4.0/), which permits unrestricted use, distribution, and reproduction in any medium, provided the original work, first published in the Journal of Medical Internet Research, is properly cited. The complete bibliographic information, a link to the original publication on https://www.jmir.org/, as well as this copyright and license information must be included. 